\title{
ÁLBUM FOTOGRÁFICO: UM MAPA DE CENÁRIOS DISCURSIVOS NA PRODUÇÃO ACADÊMICA BRASILEIRA SOBRE AULAS EXPERIMENTAIS DE CIÊNCIAS
}

\section{Photo gallery: a map of discursive scenarios in Brazilian academic articles on experimental Science lessons}

\author{
Livia de Rezende Cardoso ${ }^{1}$. Marlucy Alves Paraíso ${ }^{2}$
}

\begin{abstract}
Resumo: Neste artigo, buscamos compor um mapa dos cenários discursivos que permeiam a produção acadêmica brasileira de artigos em periódicos e eventos, teses e dissertações. Em tal exercício, foi possível perceber como os currículos das aulas experimentais são atravessados pelos discursos: da ciência moderna, da psicologia behaviorista, do método ativo, de progresso pela ciência, construtivista, da ciência dialética, de professor pesquisador, sociointeracionista, da pedagogia crítica, das tecnologias educacionais e dos estudos culturais. Argumentamos, aqui, que existem muitos cenários discursivos, compostos em meio a relações de poder-saber, construídos pela produção acadêmica brasileira, competindo e se articulando para compor uma narrativa de vida para o currículo experimental. Em certas fases, por meio de legendas e fotos, inventam-se características de racionalidade, neutralidade, empiria, objetividade. Em outras, designa-se lúdico, tecnologias e cidadania como elementos cenográficos.
\end{abstract}

Palavras-chave: Ensino de ciências. Produção acadêmica. Discurso. Experimentação.

\begin{abstract}
We have composed a map of discursive scenarios that permeate the production of Brazilian academic articles in journals and conferences, theses and dissertations. In this exercise, it was possible to see how experimental classes are traversed by the discourses of modern science, psychological, behaviorist, the active method, progress in science, constructivist science dialectic, teacher researcher, interactionism, critical pedagogy, educational technology and cultural studies. We argue that there are many discursive scenarios in the relations of power and knowledge, built during Brazilian academic production, competing and organizing to compose a narrative of life for the experimental curriculum. In certain phases, through captions and photos, this invents characteristics of rationality, neutrality, empiricism, and objectivity. In others, it defines play, technology and citizenship as scenography elements.
\end{abstract}

Keywords: Science teaching. Academic production. Discourse. Experimentation.

\footnotetext{
${ }^{1}$ Universidade Federal de Sergipe (UFS), Departamento de Educação, Avenida Ver. Olimpio Grande, CEP 49500-000, Itabaiana, SE, Brasil. E-mail: livinha.bio@gmail.com

${ }^{2}$ Universidade Federal de Minas Gerais, Faculdade de Educação, Belo Horizonte, MG, Brasil.
} 


\section{Introdução}

Ao construir álbuns fotográficos, personagens desejariam eternizar momentos importantes, registrar apenas o que deveria ser lembrado, guardar memórias que não poderiam ser esquecidas. Em semelhante movimento de fotografar personagens e cenários, compor legendas e produzir um álbum, buscamos, neste artigo, extrair fases, cronologias e sentidos dados às aulas experimentais de Ciências na produção acadêmica brasileira de teses, dissertações, artigos em periódicos, eventos e livros. Tomamos a aula experimental como objeto por entendermos que ela tem sido produzida como necessidade curricular no Ensino das Ciências. Inspiradas na perspectiva pós-crítica de currículo, buscamos problematizar o que parece "organizado, definido, sério e coerente no campo curricular" (PARAÍSO, 2003, p. 212). Montamos um álbum fotográfico com base nos discursos que inventam e compõem a experimentação em ciências. Trata-se de discursos que "engendram domínios de saber que não somente fazem aparecer novos objetos, novos conceitos, novas técnicas, mas, também, fazem nascer formas totalmente novas de sujeitos" (FOUCAULT, 2003, p. 8).

Para mapear os outros ditos das produções sobre a experimentação em ciências, inicialmente, selecionamos obras cujos títulos e conteúdos remetiam à experimentação em aulas de ciências. Além disso, consultamos os trabalhos mais citados ou que influenciaram tais produções para compor esse mapa. Em seguida, por meio de busca ${ }^{3}$ no Banco de Teses e Dissertações da Coordenadoria de Aperfeiçoamento de Pessoal de Nível Superior (CAPES), identificamos trinta e seis trabalhos que tinham as aulas experimentais em Ciências como objeto de estudo. Desses, cinco são teses e trinta e uma são dissertações defendidas em programas brasileiros de pós-graduação strictu senso em Educação ou em Ensino de Ciências no período entre 1987-2011. Consultamos três periódicos com conceito A ${ }^{4}$, encontrando dezenove trabalhos no período entre 1995-2011. Por fim, buscamos artigos publicados nos três últimos Encontros Nacionais de Pesquisadores em Educação em Ciências, identificando cinquenta e quatro trabalhos.

Utilizamos, nas análises das obras ${ }^{5}$, conceitos foucaultianos de discurso e posições de sujeito. Discurso é entendido como "princípio de dispersão e de repartição dos enunciados, segundo o qual se sabe o que pode e o que deve ser dito, dentro de determinado campo e de acordo com certa posição que se ocupa nesse campo" (FISCHER, 2001, p. 203). Assim, não se opera analiticamente de modo a buscar a verdade de um discurso. Aqui, entendemos que existem "vários outros lugares onde a verdade se forma, onde um certo número de regras do jogo são definidas - [...] a partir das quais vemos nascer certas formas de subjetividade, certos

\footnotetext{
${ }^{3}$ Palavras-chave: aula experimental, experimento, experimentação, aula investigativa, aula prática e ensino por investigação.

${ }^{4}$ Ciência \& Educação, A1; Revista da ABRAPEC, A1, e Investigações em Ensino de Ciências, A2. Qualis disponível em: <http://qualis.capes.gov.br/webqualis/ConsultaPeriodicos>. Acesso em: 12 abr. 2010.

${ }^{5}$ No total, analisamos 109 trabalhos nos formatos de tese, dissertação, artigo em periódico e publicação em evento. Ao final deste artigo, organizamos, separadamente, a lista das referências bibliográficas de tais obras analisadas.
} 
Álbum fotográfico: um mapa de cenários ...

domínios de objeto, certos tipos de saber" (FOUCAULT, 2003, p. 11) -, constituindo uma história externa da verdade. Isso possibilita que se analisem os ditos em torno das aulas experimentais, buscando-se compreender quais saberes contavam na produção desse regime de verdades e quais não foram privilegiados. Além disso, é preciso considerar que discursos "formam sistematicamente os objetos de que falam" (FOUCAULT, 2005, p. 55), construindo "lugares a partir dos quais os sujeitos podem se posicionar e a partir dos quais podem falar" (WOODWARD, 2008, p. 17). Ao se mapearem discursos que atravessam um objeto, é preciso problematizar posições demandadas aos sujeitos.

Ao compormos um rabiscado estado da arte acerca das produções sobre aulas experimentais de ciências, desejamos selecionar cenários, criar legendas e fazer aparecer conflitos, descontinuidades e articulações dos discursos que, ao atravessarem a literatura especializada, dirigem fotografias de aulas experimentais. Desse modo, aqui, os trabalhos que compõem a produção acadêmica brasileira não são apenas apresentados ou delineados. Assim, dos trabalhos analisados, tivemos o objetivo inicial de retirar os ditos em torno da experimentação para, em seguida, situá-los em contextos discursivos mais amplos, caracterizando-os. Buscamos, ainda, problematizar as demandas que foram sendo produzidas aos sujeitos professor/a e aluno/a das ciências.

Ao construírmos tal álbum, argumentamos, neste artigo, que existem muitos cenários discursivos, compostos em meio a relações de poder-saber, construídos pela produção acadêmica brasileira, competindo e se articulando para compor uma narrativa de vida para o currículo experimental. Em certas fases, por meio de legendas e fotos, inventam-se características de racionalidade, neutralidade, empiria, objetividade. Em outras, designam-se lúdico, tecnologias e cidadania como elementos cenográficos. Produzem-se, discursivamente, necessidades, urgências, caminhos e objetivos a serem alcançados por personagens que contracenaram nesses cenários. Enfim, por meio da técnica de colagem fotográfica, é possível perceber que, na literatura especializada, demandam-se conflituosas posições de sujeito com pretensões de narrar como deveria ser a vida do currículo e de seus sujeitos.

Nos itens que se seguem, desenvolvemos análises sobre o material citado de modo a dividir este artigo em seis partes. Na primeira delas, a experimentação é caracterizada em seu início na escola, bem como os princípios da ciência e da pedagogia modernas são contextualizados historicamente. A segunda parte aponta modificações advindas com discursos psicopedagógicos, políticos e econômicos. A terceira parte é formada pelos "ditos" da psicopedagogia, da formação de professores/as e da crítica à ciência moderna. Na quarta parte, analisamos os discursos de movimentos sociais em torno da ciência e do ambiente e suas influências na experimentação. Na quinta parte, trazemos o discurso das novas tecnologias e dos estudos culturais que concorrem para compor a experimentação. A sexta e última parte é destinada a algumas considerações em torno dos diferentes cenários discursivos demandados pela produção acadêmica brasileira sobre a experimentação.

\section{$\mathrm{Na}$ aurora de tempos modernos}

Se entrássemos numa aula de ciências, tendo como direção a literatura especializada acerca da experimentação em seu início no espaço escolar, facilmente nos depararíamos com o cenário de bancadas altas e limpas, microscópios, pinças, cadinhos, bisturis e vidrarias dispos- 
tos intencionalmente. Instrumentos esterilizados, luz adequada e grupo-controle pronto de modo a dominar as possíveis variáveis. Palco armado, o/a professor/a traja os princípios da ciência ao vestir o jaleco branco. Seus objetivos seriam:

[...] testar uma lei científica, ilustrar ideias e conceitos aprendidos nas 'aulas teóricas', descobrir ou formular uma lei acerca de um fenômeno específico, 'ver na prática' o que acontece na teoria, ou aprender a utilizar algum instrumento ou técnica de laboratório específica. (BORGES, 2002, p. 05)

Nesse cenário, poderíamos imaginar que o/a professor/a solicitaria aos/as seus/as alunos/as a realização de atividades práticas, o que envolveria observações e medidas acerca de fenômenos determinados por ele/a ao seguirem as instruções prescritas em roteiro.

A natureza que, ali, se ensina está para ser ordenada por uma lógica científica e, por meio de métodos rígidos, teorizada. Afinal, Comte ensinou, no século XIX, que "toda desordem aparece como uma imperfeição, uma causa de inquietude e, até mesmo, uma forma do Mal" (JAPIASSU, 2007, p. 12-13). Para pôr fim à desordem e criar uma narrativa ordenada, recorreria-se ao legado de Bacon (1988) quando se preocupou com métodos indutivos no século XVII. Segundo ele, chegar à verdade "consiste em saltar das sensações e das coisas particulares aos axiomas mais gerais" (BACON, 1988, p. 16). Igualmente empirista, David Hume (2009, p. 133), no século XVIII, acreditava que "todo raciocínio provável não é senão uma espécie de sensação". Isto é, cientistas e filósofos dependeriam unicamente da experiência.

Desde Aristóteles (1984a, p. 11), já se acreditava que "homens têm, por natureza, o desejo de conhecer". Por permear os modos de conhecer o mundo real, haveria de dar destaque à experiência sensível, o que fundaria a ideia de um sujeito empírico. Com esse pressuposto, Aristóteles (1984b, p. 143) definiu o conhecimento científico como "um estado que nos torna capazes de demonstrar". É por esse aspecto que caracterizamos, aqui, mesmo considerando-o de tradição racionalista, esse filósofo como o mais importante a fundar uma episteme empirista. Porém, é com a idealização da ciência moderna que empiria e racionalidade passariam a andar juntas. Em meio ao predomínio de um sujeito empírico idealizado pela ciência, fundaria-se um sujeito racional: aquele que explora o universo por meio da observação e do pensamento lógico. Eis que o discurso racionalista passaria a ser o eixo central para diferentes pensadores que vão se empenhar, desde então, na busca de uma marca fundamental da espécie humana. Descartes (apud CHALMERS, 1994, p. 56) nos diria que "as pessoas são capazes de estabelecer as verdades necessárias por meio da luz natural de sua razão". Um cruzamento entre discurso racional e empírico que funda uma ciência moderna. Racionalidade instrumental, observação, objetividade, organização, empirismo, pensamento cartesiano e universalismo passariam a ser peças fundamentais nesse cenário.

Se já encontramos desejos de um sujeito humano que conheça e domine a si mesmo e à natureza, nos filósofos antigos, sem dúvida, foram os arquitetos do Iluminismo, no século XVIII, com o projeto da modernidade baseado numa fé na razão, que produziram uma narrativa do homem como sujeito que descobriria a verdade. O sujeito do Iluminismo seria um indivíduo “centrado, unificado, dotado de razão, de consciência e de ação, cujo 'centro' consistia num núcleo interior, que emergia, pela primeira vez, quando o sujeito nascia e com ele se 
Álbum fotográfico: um mapa de cenários ...

desenvolvia" (HALL, 2001, p. 10). O mundo seria algo estático, uma realidade a ser descoberta pelas verdades desse sujeito.

No âmbito do pensamento iluminista, como a racionalidade do sujeito não estaria completa, a escola seria uma das instâncias permeadas pelo discurso moderno da ciência e constituída como espaço onde o homem se desfaz de sua menoridade. É por meio, sobretudo, do discurso científico e do discurso pedagógico modernos que o sujeito se tornaria civilizado, racional, autônomo e consciente (VEIGA-NETO, 2000). Se à escola coube essa missão, ao currículo das ciências coube falar de "conhecimentos válidos por sua 'verdade interna', ahistóricos e independentes das culturas onde foram gerados" (MACEDO, 2004, p. 122). De acordo com a revisão das perspectivas históricas no ensino de Ciências por investigação realizada por Deboer (2006), as justificativas para a introdução do estudo de métodos e procedimentos científicos na escola, no século XIX, partiram de influentes cientistas dos EUA e da Inglaterra que almejavam que os/as alunos/as aprendessem a desenvolver investigações científicas na perspectiva de ciência da observação e do raciocínio indutivo. Ao discorrer sobre as ideias de diversos autores da época, Deboer (2006, p. 25) classifica em três as abordagens de ensino: 1) descoberta do verdadeiro ou heurística, onde alunos/as têm o máximo de liberdade para explorar por conta própria o mundo; 2) descoberta orientada, objetivando guiar os/as alunos/as na solução de problemas propostos; 3) verificação para confirmar fatos ou princípios em laboratório.

Considerando os pressupostos da primeira forma de contracenar no cenário descrito, aproximamos tal modo de debruçar-se sobre a natureza para conhecê-la de um discurso pedagógico corrente na segunda metade do século XIX: o conhecimento pelo contato direto com as coisas, as "lições de coisas". Para Martins (2009, p. 4),

[...] o desafio que os pedagogos enfrentaram para transpor, em termos práticos, concepções filosóficas, especialmente o empirismo e sua teoria do conhecimento, para a cultura escolar, o que incluía a expressão nos manuais de ensino.

Segundo Munakata (2009), o que importa nas "coisas" seria sua utilidade para o humano. Assim, "não cabem nem beleza, nem prazer, tampouco o lúdico, o entretenimento ou o diletante. Esse mundo que se dá aos sentidos é, portanto, um mundo que deve cancelar, paradoxalmente, os sabores, os cheiros e os sons" (MUNAKATA, 2009, p. 6).

Ao contar a história da disciplina Ciências na Inglaterra no século XIX, Goodson (1995) caracteriza uma forma de ensinar e, aqui, a aproximamos do segundo modo de encenação, que buscaria guiar os/as alunos/as na solução de problemas. Inicialmente proposta para a instrução dos/as filhos/as de classes trabalhadoras, tal disciplina serviria para estimular-lhes a mente com problemas do cotidiano, seria a ciência das coisas comuns, fato que desafiou a ordem social vigente. Em resposta, classes média e alta, incomodadas com o ensino de qualidade oferecido às classes populares, propunham a substituição desse enfoque por uma abordagem mais abstrata, se caracterizando pelo conceito de "ciência pura de laboratório". Esse autor reforça que o currículo passou a "ser principalmente acadêmico e associado às disciplinas universitárias", já no fim do século XIX (GOODSON, 1995, p. 42).

Por sua vez, o terceiro ensaio entre personagens, que se aproxima da verificação de fatos, seria "cópia do modus operandi dos laboratórios do Ensino Superior, ou seja, laboratóri- 
os concebidos como lugares fechados, munidos de sistemas e experimentos prontos para a mensuração de resultados já esperados" (GIOPPO; SCHEFFER; NEVES, 1998, p. 46). Galiazi et al. (2001) pontuam que, há mais de cem anos, aulas experimentais tiveram origem na escola ao se espelharem no trabalho experimental desenvolvido nas universidades. Afinal, Comenius, Locke, Spencer, Rice e Eliot defendiam a importância de ensinar tópicos científicos com base no "contato direto com o mundo", por excelência, via experimentação (SARAIVA-NEVES; CABALLERO; MOREIRA, 2006), configurando-se como "reconstruções metacientíficas vinculadas ao empirismo" (ARRUDA; SILVA; LABURÚ, 2001, p. 97).

Em quaisquer desses modos de justificar a necessidade da experimentação, as "produções de verdades não podem ser dissociadas do poder e dos mecanismos de poder" (FOUCAULT, 2006, p. 232). Se ora a verdade é o ensino pelo contato direto com as coisas, ora é a ciência das coisas comuns que é válida. Se outrora o ensino abstrato torna-se a recomendação é porque o discurso da ciência moderna já produziu a emergência, incontestável, da experimentação no espaço escolar. Se a ciência moderna funda a escola, é por meio dos currículos de ciências, em geral, e da experimentação, em particular, que a pedagogia moderna pensará a construção de seus sujeitos modernos. Sob a legenda na aurora de tempos modernos, o primeiro cenário aqui montado teve direção dos discursos da ciência e da pedagogia modernas que permitiriam contracenar elementos empíricos e racionais. Em tais fotos, as personagens, com vestimentas e utensílios laboratoriais, seriam atravessadas por saudosos discursos que fundaram a ciência, a escola e a si mesmas. Um processo em que a humanidade criou narrativas para se reconhecer como Homo sapiens. Quaisquer que tenham sido os ensaios fotográficos entre personagens, havia desejos de: inserção do ensino do método científico na escola, produção de necessidades de se pensar o mundo e a si mesmos/as através da égide da ciência, e produção de sujeitos empíricos, racionais, lógicos e ordenadores do caos.

\section{Com meus brinquedos inovadores}

O cenário descrito anteriormente, se atravessado por discursos do início do século $\mathrm{XX}$, passaria a compor as aulas experimentais como momento em que se ensina o que é ciência. As ditas inovações no ensino das ciências só entrariam na educação brasileira com as propostas de transformação da Escola Nova (KRASILCHIK, 1987). Entraria, então, em cena “a expressão 'ensino ativo' [que] é retoricamente relacionada a uma máxima do pragmatismo e do ensino progressivo de Dewey. O ensino ativo implica que se aprende fazendo" (POPKEWITZ, 2001, p. 96). Assim, ao propor o método ativo, Dewey (1959) defendeu uma abordagem experimental para o ensino das ciências. Esse autor acreditava que os métodos científicos eram tão importantes quanto os conhecimentos (SARAIVA-NEVES; CABALLERO; MOREIRA, 2006), em que a experiência seria "o principal recurso do raciocínio científico, porque ajuda a isolar os elementos significativos, num conjunto uniforme e vago" (DEWEY, 1959, p. 195).

Tal pensamento passaria a influenciar reformas curriculares de modo a investir em participação ativa do/a aluno/a na aquisição de conhecimentos e união teoria-prática. Assim, "com o passar dos anos, os currículos de ciências e estudos sociais, por exemplo, foram organizados por atividades que se concentram em abordagens indutivas e da descoberta." (POPKEWITZ, 2001, p. 96). Nessa perspectiva, participação, método ativo, investigação, curiosi- 
dade passariam a compor outro cenário. Afinal, isso seria "o fator básico da ampliação da experiência, [...] ingrediente primário dos germes que se desenvolverão em ato de pensar reflexivo" (DEWEY, 1959, p. 45). Tal modo de pensar se daria quando se transforma uma situação de obscuridade, dúvida e conflito em uma situação clara e harmoniosa.

$\mathrm{O} / \mathrm{a}$ professor/a dessa foto deveria apresentar "problemas típicos que devam ser resolvidos por reflexão e experimentação pessoal e pela aquisição de conteúdos definidos de conhecimentos capazes de levar, mais tarde, a noções científicas mais especializadas" (DEWEY, 1959, p. 214). Para tanto, haveriam recomendações feitas por esse autor: trabalhar com projetos; ir do concreto ao abstrato; usar de modo não abusivo a linguagem (DEWEY, 1959). No discurso pedagógico do método ativo, o planejamento curricular deveria considerar "os interesses e as experiências das crianças e jovens" (SILVA, 2003, p. 23). Tal aspecto diferencia essa fotografia da anterior. No entanto, apresentam-se como semelhantes no seguinte elemento: ciência moderna. Afinal, métodos e conhecimentos científicos ainda não eram problematizados nesse currículo, tido por tradicional (SILVA, 2003).

Por outro lado, o/a professor/a do cenário descrito, se orientado/a pelos discursos do final da década de 1950, incrementaria a experimentação com kits de práticas. Muito mais como apetrechos - considerando-se que o discurso behaviorista passa a incidir sobre a escola, pensando a aprendizagem através das "máquinas de ensinar" -, experimentos aconteceriam de modo demonstrativo e valorizariam o "empirismo colorido e divertido, que supostamente motivaria o aluno" (GONÇALVES; MARQUES, 2006, p. 220). Afinal, não se poderia esquecer que "ensinar é simplesmente arranjar contingências de reforço" sob as quais o comportamento muda (SKINNER, 1972, p. 04). Moraes (1998) descreve esse experimento demonstrativo como atividade prática voltada à verificação de uma lei já formulada.

A esse contexto, soma-se o lançamento do Sputnik pela União Soviética, em 1957: período de pós-guerra, industrialização, desenvolvimento tecnológico e científico. Um contexto que produziu o discurso de progresso pela ciência e o circulou em diferentes espaços. Assim, cientistas americanos, que ocupavam uma posição de prestígio, viram no campo educacional uma área potencial de influência. Surgiram grandes projetos curriculares: Biological Science Curriculum Study (BSCS), Chemical Education Material Study (CHEMS), Physical Science Study Cimmittee (PSSC) e cursos Nuffield (BARBERÁ; VALDÉS, 1996). Tais projetos alteraram os programas das disciplinas científicas - nos Estados Unidos e, posteriormente, em países europeus - e se propunham a "substituir os métodos expositivos pelos métodos ativos, com preponderância do laboratório" (KRASILCHIK, 1987, p. 07). As aulas práticas deveriam, então, propiciar atividades que auxiliassem os/as alunos/as na compreensão de conceitos.

No Brasil, investimentos nessa ideia de inovação começaram anteriormente a esse período, ainda sob influência do discurso do método ativo produzido pela Escola Nova, com a instalação do Instituto Brasileiro de Educação, Ciência e Cultura (IBECC) em 1946. Porém, foram as influências dos discursos behaviorista e do progresso pela ciência que proporcionaram a implantação de projetos escolares como feiras, museus e clubes de Ciências e, na década seguinte, os primeiros kits para o ensino experimental. Houve, sobretudo, forte influência nos planejamentos curriculares expressa pelo excessivo foco nos objetivos, competências e comportamento a serem alcançados (KRASILCHIK, 1987), o que tornou possível, hoje, existirem publicações acadêmicas em revistas ${ }^{6}$ e eventos ${ }^{7}$ acerca de habilidades e competências numa 
experimentação. É esse foco nos objetivos de ensino que marca uma maior diferença entre o discurso progressista de Dewey e a psicologia comportamentalista de Skinner.

Outra descontinuidade nos cenários, apesar de ambos serem nomeados como tradicionais, é que Skinner (1972) aproxima-se mais fortemente da ideia taylorista de currículo. Nessa perspectiva, considera-se que os objetivos de ensino estariam dados pelas exigências profissionais da vida adulta (SILVA, 2003), não havendo um foco no/a aluno/a como propunha Dewey. As citadas inovações no currículo de Ciências surgiram, para Ferreira (2007), em meio à dualidade entre ensino propedêutico e profissional, ficando restritas, em grande parte, ao ciclo ginasial. Ao analisar um currículo específico datado daquela época, essa autora afirma que tais inovações foram expressas "tanto nos critérios de seleção e de organização dos conteúdos de ensino quanto na defesa de uma metodologia de caráter experimental" (FERREIRA, 2007, p. 130) para manutenção do prestígio da disciplina.

Embora esse cenário tenha ganhado a contribuição de mais discursos, outros ditos sobre a ciência ainda não haviam se reformulado. Como consequência, as aulas experimentais continuavam a ser entendidas como o elo entre "todos os níveis de ensino e entre o ensino e a pesquisa científica que ocorria nos Institutos de Pesquisa e nos laboratórios das grandes indústrias" (SÁ, 2009, p. 18). Essa prática indutiva de ciência apareceria "como simples manipulação de variáveis, deduzindo leis (teorias) a partir dela própria ou da sua sistemática reprodução [o que leva à] generalização (indução)" (PRAIA; CACHAPUZ; GIL-PÉREZ, 2002, p. 256) a partir de significativas observações. Defendendo a tese de que as ideias positivistas influenciaram e ainda influenciam práticas pedagógicas da atualidade, Giordan (1999, p. 45) considera que aulas experimentais serviriam também como "veículo legitimador do conhecimento científico, na medida em que os dados extraídos dos experimentos constituíam a palavra final sobre o entendimento do fenômeno em causa".

Ao serem atravessados por discursos de competências, planejamento de objetivos ${ }^{8} \mathrm{e}$ melhoria de recursos didáticos ${ }^{9}$ que compõem um experimento, alguns trabalhos acadêmicos foram produzidos com essas direções. Souza Filho (2004) fez uma análise, em livros didáticos de Física, enfocando as atividades experimentais referentes aos conteúdos da Eletricidade e Magnetismo, verificando a presença de falhas conceituais. Diniz (1992) realizou um estudo em kits do projeto "experimentoteca pública", concluindo que o/a professor/a teria papel central para que este método funcione. Silva (1999) constatou que propostas de experimentação nos livros didáticos são utilizadas para comprovar o conteúdo dos textos, sendo apresentadas de forma a não instigar a curiosidade e espírito científico.

\footnotetext{
${ }^{6}$ Fernandes; Silva (2004); Suart; Marcondes (2008).

${ }^{7}$ Suart; Marcondes; Carmo (2009).

${ }^{8}$ Galiazi et al. (2001); Malheiro (2011); Saraiva-Neves; Caballero; Moreira (2006).

${ }^{9}$ Recursos que auxiliam na experimentação: Francisco; Francisco Junior (2011), Latini; Canesin; Cotelo (2011). Experimentações em livro didático: Carneiro; Oliveira (2011); Gardelli; Neves (2011); Güllich; Silva (2011); Pedroso; Rosa; Amorim (2009); Santiago; Costa; Guimarães (2011); Wesendonk; Rodrigues; Terrazzan (2011). Em museus: Bonatto et al. (2009).
} 
Álbum fotográfico: um mapa de cenários ...

Ao formular uma legenda na qual se anuncia a chegada de brinquedos inovadores, esse cenário discursivo marca a presença do discurso pedagógico do método ativo, behaviorista, do progresso pela ciência e de seus enunciados de inovação, mudança, ação e modernidade. Um currículo que desejaria sujeito ativo, prático, progressista, democrático, científico, moderno. Se, no cenário anterior, celebrava-se a aurora de uma ciência moderna, nessa fotografia comemoram-se os novos e inovadores ditos que vêm para consolidar sua permanência no currículo escolar. Afinal, "por trás de todo saber, de todo conhecimento" - aqui, os saberes sobre ensino experimental - "o que está em jogo é uma luta de poder" (FOUCAULT, 2003, p. 51). Assim, os elementos que estão em cena nessa fotografia são promessas salvacionistas de uma educação democrática para a massa da população e de um progresso científico para o bem-estar da humanidade. Uma união que culminaria em maiores investimentos e prestígio para o ensino da ciência.

\section{No centro das atenções}

Se o/a professor/a imaginado/a no cenário anterior realizar a experimentação considerando conhecimentos prévios dos/as alunos/as, diálogo, práticas de ação e reflexão, solução de problemas, habilidade de pesquisa, interdisciplinaridade, questionamentos e trabalho em grupo (MORAES, 1998), certamente já estaria atravessado/a pelo discurso construtivista. Como consequência, o cenário de sua aula passaria a integrar elementos mais dinâmicos por meio dos quais os/as estudantes ganhariam papel central, liberdade e autonomia (POPKEWITZ, 1998; WALKERDINE, 1998). Afinal, para Lajonquière (2009, p. 33), "a pedagogia moderna nas suas diversas versões está sempre centrada no aluno".

A produção desse discurso em torno da aprendizagem dos conteúdos científicos teve destaque na década de 1980. Falava-se da necessidade de se concretizar o ensino que, de acordo com o pensamento piagetiano, deveria ter cunho experimental e estar associado à argumentação teórica. Nesse sentido, Azevedo (2004) destaca etapas dessa forma de encenar uma aula experimental: 1) formulação do problema de modo a estimular a curiosidade; 2) levantamento de hipóteses pelos/as alunos/as em busca da solução do problema; 3) elaboração do plano de trabalho sob a orientação do/a professor/a; 4) montagem do arranjo experimental e coleta de dados; 5) análise dos dados; e 6) conclusão. Desse modo, Carvalho et al. (1998, p. 20) defendem que o problema seria "a mola propulsora das variadas ações dos alunos: ele motiva, desafia, desperta o interesse e gera discussões". Além disso, abriria a experimentação para as possibilidades do erro e do acerto, confrontaria o sujeito e seus modelos mentais, configurando-se como um acordo na direção do que é cientificamente aceito e dialogável com cientistas (GIORDAN, 1999, p. 46). Esse modo de conceber a experimentação alertaria para o cuidado que o/a professor/a deve ter em hierarquizar os fenômenos a serem estudados a depender do nível cognitivo dos/as alunos/as.

No discurso construtivista piagetiano, o conhecimento é produzido pela atividade cognitiva de criação de sentido pelo/a aluno/a, sendo primordial seu papel. Em tal situação, "o conhecimento não procede nem da experiência única dos objetos nem de uma programação inata pré-formada no sujeito, mas de construções sucessivas com elaborações constantes de estruturas novas" (PIAGET, 1976, p. 367). Ao/à professor/a, caberia "levantar novos problemas à medida que resolve os precedentes" (PIAGET, 1976, p. 34). Nesse processo, 
jogo e brincadeira destacam-se como material pedagógico (PIAGET, 1969). Ao estipular um saber biológico sobre fases de desenvolvimento, exigem-se certas formas de conduzir a experimentação. Assim, entendemos o lúdico como aquilo que Foucault $(2007$, p. 8) denominou por "efeitos de verdade no interior de discursos que não são em si nem verdadeiros nem falsos".

A visita de novos elementos cenográficos a esse cenário discursivo impulsionou a produção de trabalhos sobre alunos/as em periódicos ${ }^{10}$, eventos ${ }^{11}$, teses e dissertações. Afinada à concepção de que se aprende através do lúdico, a pesquisa de Higa (1997) propôs o uso de um material lúdico e de conteúdo científico como suporte às atividades em torno do conteúdo Óptica. Do mesmo modo, Pereira (2007) teve como objetivo investigar o impacto de atividades museais concernentes a fenômenos da óptica em museu de ciências e ambientes escolares, demonstrando que atividades lúdicas experimentais exerceriam impacto favorável sobre os/as estudantes. Marchezini (2008) deteu-se nas mudanças conceituais acerca do conteúdo Torque, cujos resultados apontaram para o desenvolvimento do conceito pretendido. Casagrande (2006) pesquisou o papel do ensino experimental no ensino de solo, o que a levou a concluir que esse contribuiria na geração de reflexões sobre conhecimentos prévios dos/as alunos/as, elaborados dentro de seu contexto escolar. Alves Filho (2000) propôs a atividade experimental como um novo instrumento de ensino, cuja função seria a de ser mediadora do diálogo construtivista entre professor/a, estudante e conhecimento científico. Abegg (2004) analisou um trabalho de investigação-ação escolar realizado com professoras, verificando que haveria aumento na cognoscência em termos da problematização de situações-problema e da tomada de decisões dos sujeitos envolvidos.

No final da década de 1970, outros discursos sobre ciência passam a incidir sobre o currículo de Ciências. Valoriza-se o conhecimento científico em uma perspectiva de processo. Isto é, passa-se de uma "ciência cognitiva" para uma "ciência dialética" (LACEY, 1998), influenciada por filósofos como Popper, Kuhn e Feyerabend, que problematizam a ideia "empiristaindutivista na produção do conhecimento" (GONÇALVES; MARQUES, 2006, p. 220). Nessa perspectiva, a experiência "deve ser guiada por uma hipótese, que procura funcionar, sobretudo, como tentativa de sua retificação e questionamento - ela interroga, problematiza -, conduzindo, muitas vezes, a outras hipóteses" (PRAIA; CACHAPUZ; GIL-PÉREZ, 2002, p. 257). $\mathrm{O}$ aspecto central desse discurso da ciência dialética

[...] é a compreensão da ciência como produto do uso do raciocínio hipotético-dedutivo. A ciência seria um processo de superação de teorias por meio do contraste empírico, o que levaria a uma aproximação sucessiva da realidade por meio de teorias cada vez mais verdadeiras. (ARRUDA; SILVA; LABURÚ, 2001, p. 98)

\footnotetext{
${ }^{10}$ Hoernig; Pereira (2004); Matos; Valadares (2001); Sousa; Moreira; Matheus (2005).

${ }^{11}$ Como aprendem por modelos mentais: Abib; Testoni, Cunha (2011); Amon-Santarelli; Muramatsu (2011); Campos; Araújo (2009, 2011); Morrone; Araújo; Amaral (2009); Rosa; Alves Filho (2011); Silva et al. (2011); e em grupo: Savi (2007).
} 
Álbum fotográfico: um mapa de cenários ...

Isto é, no método dialético,

[...] primeiro, se afirma uma tese [...], depois, apresenta-se uma antítese [...] que é provocada pela aparição de outros pontos de vista, surgidos com base no exame crítico que se fez. Enfim, apresenta-se uma síntese, que é uma nova maneira de ver, resultante do processo crítico. (FOUREZ, 1995, p. 37)

Essa atualização do discurso da ciência produz uma verdade para a ciência das aulas experimentais que "mascara a vontade de verdade" (FOUCAULT, 2009, p. 6).

Como se trata de realizar tudo isso em laboratório escolar, preconizam-se, ainda, as etapas antes citadas de Azevedo (2004), primando pelo cuidado epistemológico sugerido por Arruda, Silva e Laburú (2001). Assim, no âmbito escolar, isso se traduziria numa aula experimental como potencial educativo por repetição do processo utilizado pelos cientistas em seus laboratórios, sem, segundo Krasilchik (1988, p. 56), cair na "caricatura ingênua da experimentação como receita". Por conta disso, é comum, hoje, a recomendação de que os currículos de Ciências incorporem temas de História e Filosofia da Ciência e enfatizem a dimensão histórico-social do processo de produção de conhecimentos na ciência.

Tal recomendação discursiva permitiu a existência de quatro trabalhos acadêmicos sobre epistemologia da ciência e aulas experimentais, bem como publicações de artigos em periódicos ${ }^{12}$ e eventos ${ }^{13}$. Silva (1999) buscou compreender as concepções epistemológicas de professores/as de um curso de licenciatura, evidenciando a predominância da concepção empírico-positivista quando retrata a transmissão do conhecimento pelo/a professor/a. Schein (2004) investigou como um experimento centrado na produção e na aplicação de um objeto técnico, a Balança Analítica, pode favorecer a aprendizagem e o estabelecimento de relações entre referencial empírico, conceitos, leis, teorias e linguagens simbólicas e matemáticas. Baratieri (2004) investigou as concepções de alunos/as a respeito das aulas experimentais de Química, enfocando em motivação, interação e visão de ciência. Moreira (2005) concluiu que a cultura científica estaria presente nas aulas experimentais pesquisadas e que os/as alunos/as apreenderam. Zuliani (2000) avaliou a aplicabilidade do método investigativo em atividades práticas, no qual a metacognição proporcionaria um efetivo incremento na aprendizagem.

Apesar de o/a aluno/a tornar-se, discursivamente, o centro das atenções nesse cenário, a função do/a professor/a passa a ganhar muitos incrementos discursivos. Segundo Lüdke (2001), a ideia de professor pesquisador sobre a prática surgiu com Stenhouse na década de 1970, para o qual "o professor deveria experimentar em cada sala de aula, tal como num laboratório, as melhores maneiras de atingir seus alunos, no processo de ensino-aprendiza-

${ }^{12}$ Arruda; Silva; Laburú (2001); Gomes; Borges; Justi (2008); Gonçalves; Marques (2006); Praia; Cachapuz; GilPérez (2001).

${ }^{13}$ Boss; Souza Filho; Caluzi (2009); Caluzi; Souza Filho; Boss (2007); Guedes; Baptista (2011); Maruyama; Braga; Guerra (2011); Monteiro Júnior; Caluzi; Carvalho (2009); Niezer; Silveira; Sauer (2011). 
gem" (LÜDKE, 2001, p. 79). De acordo com Santos (2001), tal ideia foi reforçada por Schön (2000) na década seguinte, que trazia a concepção de profissional reflexivo que elimina a distância entre pesquisa e atividade profissional através dos conceitos de reflexão na ação, sobre a ação e sobre a reflexão na ação.

Tal investimento discursivo é expresso no grande número de teses e dissertações em que se investiga a ação docente em aulas experimentais, bem como de artigos em periódicos ${ }^{14}$ e eventos ${ }^{15}$. Hernandes (2002) conclui que a segurança do/a professor/a em levar algo inovador e diferenciado do tradicional seria essencial para a realização de um bom trabalho. Vasnizi (2000) identificou a visão docente sobre a utilização de experimentos de óptica, entendendoos como ferramenta para o desenvolvimento de competências. Lima (2004) observou como professores/as de Química refletem sobre sua prática docente e mudam visões simplistas ao realizarem experimentações após participarem de curso de atualização em eletroquímica. Araújo (2007) estudou as prioridades de professores/as e licenciandos/as ao selecionarem experimentos, constatando discrepâncias nas priorizações entre os grupos. Outro grupo de pesquisas (KANBACH, 2005; MAMPRIN, 2007; SALVADEGO, 2007; TITONI, 2008) buscou entender razões da utilização ou não de experimentos na escola.

Ao compor uma legenda que anuncia que há algo no centro das atenções, o cenário curricular descrito mostra cuidado com todos os componentes cenográficos: conhecimentos prévios, situação-problema, mudança conceitual, importância do erro, ciência como processo, prática reflexiva e investigação-ação do/a professor/a. Ao produzir enunciados de que o/a aluno/a é o centro da pedagogia, de que a produção do saber científico precisa ser problematizada e que é necessário investir na formação inicial e continuada do/a professor/a, esse currículo desenvolve estratégias para tornar-se o próprio centro. Ao ser atravessado por discursos diversos - ciência dialética, psicologia construtivista e professor-pesquisador -, tal cenário discursivo buscou atualizar estratégias e técnicas em torno dos sujeitos das aulas experimentais de Ciências. Afinal, aos indivíduos que se deseja transformar, seria necessário produzir um determinado saber, uma determinada técnica (FOUCAULT, 2007). Isto é, com a chegada de tais discursos ao cenário educacional, prima-se por um sujeito criativo, autônomo, lúdico e investigativo.

\section{Com a turma do movimento}

Quando o cenário discursivo das aulas experimentais passa a dar maior ênfase a problemáticas sociais, contextualização, formação de cidadãos críticos e ciência como prática social, esse currículo é atravessado por três discursos, que permearam o contexto educacional

\footnotetext{
${ }^{14}$ Assis; Laburú (2009); Laburú (2005); Laburú; Barros; Kanbachi (2007); Pena; Ribeiro Filho (2009); Ramos; Rocha (2008).

${ }^{15}$ Binsfeld; Auth (2011); Cardoso; Suart (2011); Feitas (2011); Firme; Galiazzi (2011); Gonçalves; Marques (2011); Gondim; Mol (2007)); Mamprin; Laburú; Barros (2007); Marques (2011); Lima; Marcondes (2011); Moura; Chaves (2009, 2011); Oliveira; Araújo, Prado (2011); Ozório; Ferreira; Silva (2009); Porto et al. (2011); Salvadego; Laburú; Barros (2007); Santana; Salomão (2011); Silva; Marcondes; Akahoshi (2011); Silva et al. (2011); Wyzykowski et al. (2011).
} 
Álbum fotográfico: um mapa de cenários ...

nas décadas de 1970-80: do movimento Ciência, Tecnologia, Sociedade (CTS), da pedagogia crítica e da psicologia sociointeracionista. Nos currículos de Ciências, esses discursos se conectam, de modo que colocariam "o ensino de ciências numa perspectiva diferenciada, abandonando posturas arcaicas que afastam o ensino dos problemas sociais" (TEIXEIRA, 2003, p. 182). Além disso, solicitariam "um novo tipo de profissional da educação" já que deixariam de "depositar conteúdos na cabeça dos educandos, para assumir o papel de catalisador do processo de ensino e aprendizagem" (NASCIMENTO, 2008, p. 78).

Essa ideia de que ciência e tecnologia afetam a humanidade inteira, presente no discurso CTS, produziria a necessidade de um constante debate em torno dos malefícios e benefícios socioambientais advindos do discurso do progresso utilitário pela ciência. Essa seria "uma tarefa não apenas para especialista, mas para todos os cidadãos - e especialmente para todos os professores de ciência, pela responsabilidade que têm na determinação das concepções que os alunos vêm a adotar" (OLIVEIRA, 1999, p. 191). Para o/a professor/a desse cenário, a tarefa da educação científica seria, também, "desenvolver a autoconsciência crítica sobre o caráter da atividade científica e de suas aplicações e sobre as escolhas com as quais se defrontam seus participantes responsáveis" (LACEY, 1998, p. 139). Além disso, a própria experimentação precisa adequar-se ao discurso socioambiental, como é visto no artigo de Silva (2008). Do mesmo modo, Santos (2003), em trabalho dissertativo, abordou um projeto de formação de professores/as, desenvolvendo o conteúdo específico de mecânica através de abordagem experimental utilizando materiais de fácil obtenção e baixo custo.

$\mathrm{Na}$ experimentação atravessada por esse discurso, o/a professor/a não poderia esquecer-se de abarcar a dimensão social da problemática. Partiria daquilo que é vivenciado pelos/as alunos/as e dialogaria com a ciência. Questionaria-se uma ciência neutra, passando a ser entendida como produto da maneira de se descobrirem fatos, perdendo seu status de verdade absoluta (NEHRING et al., 2000). Evidenciaria a necessidade de mostrar o contexto das descobertas científicas, aproximando-o do que acontece nas aulas: "contribuição de várias pessoas" em qualquer atividade científica; "a presença constante do erro e da dúvida" ao se formularem teorias; "que não há heróis e vilões" nessa conjuntura; "a contradição de algumas idéias" (MARTINS, 1998, p. 20). Primaria-se por "ensino de ciências e cidadania" (KRASILCHIK; MARANDINO, 2004), em que a prática englobaria "a sociedade nos seus aspectos políticos, culturais e sócio-econômicos” (GOUVEIA, 1994, p. 13).

Esse cenário ainda é guiado pelo discurso da pedagogia crítica. Afinal, é tempo de desconfiar do "status quo, responsabilizando-o pelas desigualdades e injustiças sociais, [...] de questionamento e transformação radical” (SILVA, 2003, p. 30). É momento de dar acesso ao conhecimento científico para compor um quadro em que indivíduos/as, antes oprimidos/as, tornem-se cidadãos/ãs. Tal ideia de cidadania seria colocada no currículo de ciência como um estado em que as pessoas seriam alfabetizadas cientificamente, saberiam ler a linguagem em que está escrita a natureza. Por outro lado, o não ser estaria ligado à incapacidade de fazer uma leitura do universo, dos fenômenos que cercam a vida diária (CARDOSO, 2009). Portanto, o ensino de Ciências passaria a ser entendido por "uma postura mais holística que contemple aspectos históricos, dimensões ambientais, posturas éticas e políticas, mergulhados na procura de saberes populares e na dimensão da etnociências" (CHASSOT, 2003, p. 13).

Tais discursividades acerca de contextualização, conhecimentos prévios e mudança conceitual produziram o que ficou conhecido, no ensino de ciências, por ciência do senso 
comum. Uma ciência própria da sala de aula, que seria utilizada para interagir e fomentar pontos de conflito com a ciência de laboratório, o que geraria empenho do/a professor/a para solucionar esse impasse por meio do binômio observação-experimentação. Exercício que provocaria a produção do conhecimento "em sua interação com a Natureza! [...] tendo em vista o desvelamento das concepções e a interiorização do conhecimento pelo aluno" (GIOPPO; SCHEFFER; NEVES, 1998, p. 48).

No discurso sociointeracionista, a linguagem apresentaria papel fundamental. Nesse sentido, Vygotsky realizou pesquisas para entender as funções psicológicas superiores, compreender que os seres humanos possuiriam certo nível elementar de desenvolvimento que foi adquirido pelo desenvolvimento filogenético da espécie, mas que, para atingir funções superiores, haveria a necessidade de interação com o outro. Além disso, Vygotsky (2009) estabeleceu uma relação entre pensamento e fala. Essa ligação se modificaria e se ampliaria no próprio processo de desenvolvimento do pensamento e da palavra. Para Vygotsky (2009), pensamento e fala se iniciariam pela fala social, passando pela fala egocêntrica, atingindo a fala interior, que seria pensamento reflexivo.

Um dos pontos fundamentais do discurso vygotskyano seria demonstrar que as funções psicológicas superiores e a constituição da subjetividade teriam "sua origem em processos sociais de interação pela linguagem" (SOUZA, 1994, p. 94). Ao enfocar na cultura, Vygotsky considerou o indivíduo como ser social, que nasce em um mundo produzido e organizado por homens segundo princípios lógicos. Por conseguinte, muito embora Vygotsky não tenha eliminado a dimensão biológica,

[...] a capacidade de produzir e de reapropriar-se do produto da própria atividade [...] coloca a espécie humana acima da or dem biológica e a introduz na ordem da cultura, a qual não elimina aquela mas lhe confere uma nova forma de existência: a simbólica. (PINO, 2001, p. 41)

As verdades desses discursos - do CTS, da pedagogia crítica, da aprendizagem significativa e da psicologia sociointeracionista -, que produzem efeitos na experimentação em ciências, atuam estrategicamente sobre cultura local, cotidiano, contexto de professores/as e alunos/as para ensinar conhecimentos científicos. Seria um investimento "na articulação entre poder e saber, em cujo interior se produz o sujeito" (PARAÍSO, 2006, p. 102). Nesse cenário discursivo, os sujeitos são produzidos como sujeitos críticos e dialéticos. Toda essa produção discursiva tornou possível algumas publicações em revista ${ }^{16}$, em eventos ${ }^{17}$, dissertações e tese. Capechi (2004), a partir de pesquisa, concluiu que a demonstração investigativa proporcionou um trabalho com habilidades de argumentação. Nesse mesmo sentido, Barbieri (2004) anali-

\footnotetext{
${ }^{16}$ Gaspar; Monteiro (2005); Villani; Nascimento (2003).

${ }^{17}$ Como se desenvolve a argumentação: Araújo; Mortimer (2009); David; Borges (2007); Moreira; Fernandez; Trentin (2011); Suart; Marcondes (2008); e a aprendizagem por contextualização do conteúdo: Araújo et al. (2011); Merazzi; Oaigen (2009).
} 
Álbum fotográfico: um mapa de cenários ...

sou como se dá o processo de construção da argumentação nas aulas experimentais de química. Monteiro (2002) avaliou as atividades experimentais de demonstração dentro da sala de aula, concluindo que essa teoria orienta adequadamente atividades e oferece parâmetros para que elas possam se constituir em um meio eficaz para auxiliar o desenvolvimento de interações sociais, e, por consequência, de aprendizagem.

Estabelece-se, então, um conjunto de pressupostos discursivos nesse cenário da experimentação - cotidiano, contextualização, prática social, materiais de baixo custo e de fácil obtenção, ciência como vilã, ciência não utilitarista, aluno/a cidadão/ã, formação de conceito e funções superiores, problematização - para materializar o principal objetivo da Educação em Ciências: "chegar a ciência, não apenas a alunos que vão seguir estudos, mas também proporcionar [...] uma cultura científica básica ao conjunto da população" (FERNANDES; SILVA, 2004, p. 46). Ao pretenderem que o ensino atinja tal objetivo, tais ditos advindos das formações discursivas citadas defenderiam que "uma parte importante do currículo é a familiarização com esse mundo e o recurso ao laboratório é fundamental" (SARAIVA-NEVES; CABALLERO; MOREIRA, 2006, p. 389).

Esse currículo foi engendrado pela produção acadêmica especializada em um cenário discursivo de popularização, cidadania, contextualização, problemáticas ambientais e alfabetização científica. Ao compor uma legenda que o associa a movimentos sociais, esse currículo marca um vínculo com perspectivas críticas. Mais que isso, ao contracenarem juntos, o discurso da pedagogia crítica e o discurso da ciência moderna entram em conflituoso embate. Se, por um lado, o discurso científico almeja a popularização da ciência com amplo acesso e divulgação do conhecimento científico, o discurso da pedagogia crítica prescreve como isso tem de ser feito: de modo a dizer que a ciência não se constitui como verdade absoluta ou saber neutro. Do mesmo modo, ao submeter-se a tal prescrição quando se junta ao discurso crítico com intenções de maior prestígio, o discurso científico torna possível que a sua popularização produza e reinvente sujeitos sob a égide da empiria racional.

\section{Recebendo antigas e novas visitas}

Seria possível pensar em mais alguma forma de fotografar o currículo de aulas experimentais? Com os diversos ditos disponibilizados, quais outras metodologias inovadoras ainda seriam produzidas como necessárias? Que componentes e personagens seriam convocados/as para compor outro cenário? Como a questão da aprendizagem dos conteúdos científicos continua a ser vista como problema na educação brasileira - segundo Silva, Mettrau e Barreto (2007, p. 446), "ao se analisar o desempenho dos alunos, retomam-se as discussões sobre a falta de experimentação e o ensino livresco das Ciências" -, esse currículo não para de inventar e reinventar possibilidades. Um exemplo de reinvenção e atualização é o discurso das novas tecnologias no ensino de Ciências (CARDOSO; OLIVEIRA, 2010).

Se, no início do século XX, Skinner (1972, p. 27) afirmou que a educação precisaria "tornar-se mais eficaz" por meio de seus métodos e "máquinas de ensinar", o discurso de novas tecnologias prediz que "computador é, quando usado adequadamente, uma poderosa ferramenta para melhorar a qualidade do aprendizado" (SANTANA; MEDEIROS, 2008, p. 4). Atualizando o discurso comportamentalista e tradicional de currículo que investiu no planejamento de objetivos e competências, Perrenoud (1998) sugere que, para ocorrer melhorias 
na aprendizagem e familiarizar os/as alunos/as com as novas ferramentas de informática no trabalho intelectual, seria necessário desenvolver competências ${ }^{18}$.

Para atender a essa recomendação discursiva, outro cenário para aulas experimentais poderia ser construído adicionando-se softwares computacionais de simulação ou de tratamento dos dados obtidos após alunos/as e professores/as manipularem uma prática. Esses aparatos tecnológicos auxiliariam na aprendizagem dos métodos e dos conhecimentos científicos por ensinarem como se dispor, organizar, padronizar e fazer leituras dos resultados de uma experiência. Tais desejos foram concretizados em alguns trabalhos acadêmicos ${ }^{19}$ que se deixaram atravessar por esse discurso. J. C. N. Alves (2000) apresentou um programa para aquisição e discussão de dados, tendo em vista os procedimentos de uma aula experimental de mecânica. Sá (2003) demonstrou um sistema de aquisição automática de dados, concluindo que o mesmo contribuiria para romper com o enfoque livresco, fragmentado e teórico que domina o ensino. Miquelin (2003) trabalhou em ambiente multimídia-telemático, apontando esta abordagem como possível alternativa para o ensino que vise o trabalho reflexivo-crítico. Contemporâneo a esse cenário, o discurso produzido pelos Estudos Culturais da Ciência, que problematiza discursos, adentrou o currículo de aulas experimentais adicionando mais componentes à cena: as disputas culturais. A cultura já havia sido colocada na fotografia cuja legenda foi denominada por Com a turma do movimento. Nela, o discurso sociointeracionista havia solicitado tal elemento. Porém, nessa nova foto, a cultura ganha uma outra perspectiva. Se naquela a cultura era entendida como conjunto de conhecimentos científicos e universais a serem transmitidos/construídos entre alunos/as e professores/as, aqui, a cultura passa a ser entendida como campo de significações, como disputas que produzem e inscrevem diferenças e identidades (SILVA, 2003). Interessaria, agora, focar em categorias como: infância, corpo, gênero, sexualidade, raça/etnia, normatização, científico e não científico, nas aulas experimentais. Além disso, seria necessário vê-las em relação umas com as outras.

Com menor número de trabalhos acadêmicos, essa fotografia seria composta por ditos que ainda não circularam por aqui. Seu campo de investigação estaria preocupado com "práticas através das quais o conhecimento científico é articulado e mantido em contextos culturais específicos, bem como é transferido e se estende para outros contextos" (WORTMANN; VEIGA-NETO, 2001, p. 35). Além disso, sua atenção "não é com o que seja real" (AMARAL, 2000, p. 147) ou "descrever o mundo tal como ele é" (SANTOS, 2000, p. 233), mas como mundo, natureza e humano são produzidos na linguagem. Os/as cientistas, portanto, ao produzirem ciência e seus saberes, são considerados/as, nesse cenário, como aqueles/as que "exercem uma profissão literária" (LATOUR; WOOLGAR, 1997, p. 45).

Vinculados a esse cenário, encontramos um trabalho em evento (CARDOSO, 2011) e duas dissertações. Tomelin (2003) constatou que, entre alunos/as pesquisados/as, haveria o predomínio de ideias ligadas à epistemologia positivista em relação aos significados de ciência e cientista. Por sua vez, Oliveira (2005) analisou os enunciados científicos nos laboratórios de

${ }^{18}$ Entre as dez competências elencadas por esse autor, a oitava se refere ao uso da informática.

${ }^{19}$ Publicados em eventos, foram encontrados os seguintes trabalhos: Bezerra Jr. et al. (2011); Libardoni; Sauerwin; Alves (2011); Vieira; Meirelles; Rodrigues (2011). 
Álbum fotográfico: um mapa de cenários ...

ciências de Ensino Médio, concluindo que não seria possível entender as atividades experimentais de ciência escolar com base na análise dos conteúdos e manuais que são produzidos na escola ou dissociadas da ecologia em que atuam. Isto porque são o produto de negociação específica.

Durante a composição dessa última fotografia, tivemos o intuito de marcar como antigos e novos discursos atualizaram-se, inscreveram-se e compuseram o currículo de aulas experimentais. Alguns revisitaram o currículo para reiterar, reforçar e repetir ideais que engendraram necessidades de eficácia educacional, de primazia da técnica e de modernização do ensino, enfeitando o cenário da experimentação com equipamentos informatizados e softwares para simulação e tratamento de dados. Um discurso pedagógico que se somou ao discurso de ciência moderna pela priorização da eficácia, do utilitarismo, da técnica, da padronização. Ao passo que outros discursos elegem seus interesses no nível da significação, da cultura, da produção, da linguagem, da inscrição.

\section{Desejos de uma colagem}

Todos os cenários discursivos construídos para este álbum nos contam como a experimentação foi se constituindo na escola, o modo como é entendida atualmente e o papel que ocupa ao compor currículos de Ciências. A partir desse exercício de arranjar cenários, criar legendas e, assim, compor um ensaio fotográfico, folheamos suas páginas com interesses póscríticos. Partimos para apreciação sem intenção de contemplação. Quisemos, por outro lado, visualizar este álbum como um histórico não linear e conflituoso. Em tal exercício, buscamos por técnicas, procedimentos discursivos e modos de subjetivação operados em sua constituição. Cometemos, em seguida, o ato de nomeá-lo por currículo experimental. Um currículo produzido sob direção dos discursos que ditam verdades na produção acadêmica brasileira de como se deve viver, sentir e pensar aulas experimentais.

Em tal produção, muito se debate, formula e publica acerca de aulas experimentais. Por vezes, discutem-se bases epistemológicas da experimentação e concepções de ciência. Em outras, prima-se pelos/as alunos/as, definindo competências que deveriam ser desenvolvidas ou meios que os/as tornariam elementos centrais no processo de ensino-aprendizagem. Alguns/algumas empenham-se em estudos com sugestões de experimentos sobre determinados conteúdos ou para diagnosticar práticas existentes. Outros/as apostam em pesquisas que buscariam identificar os componentes necessários a uma suposta e eficiente formação do/a professor/a para o ensino investigativo. É, em busca de uma melhor compreensão das relações de poder investidas, das consequências políticas e dos modos de subjetivação implicados nessas verdades, saberes e ditos sobre a experimentação, que analiso as condições de emergência e consolidação do currículo experimental.

A partir da produção científica acerca das aulas experimentais, seria possível pensar, agora, como discursos da ciência moderna, das teorias curriculares, das pedagogias e das psicologias querem o currículo experimental. No espaço reservado aos recursos, poderíamos fotografar: lupas, cadinhos, pipetas, jalecos, balanças, jogos, brincadeiras, músicas, noticiários, computadores, simuladores. Nas páginas dos procedimentos, poderíamos colar fotografias dos seguintes componentes: atenção ao/à aluno/a, identificação dos subsunçores, aproveitamento dos conhecimentos prévios, exploração do ambiente, problematização do conteúdo, 
confronto com os saberes cotidianos, definição de situações-problema, delimitação da ciência e não-ciência, exploração da interatividade e autonomia, controle da observação e condução da investigação. Por outro lado, poderíamos compor uma sessão fotográfica destinada aos resultados esperados: mudança conceitual, racionalidade, argumentação, pensamento lógico, criticidade, cidadania, alfabetização científica e agir cientificamente.

Pensar na constituição discursiva do currículo experimental e dos saberes que o compõem é entender que "a história de um conceito não é, de forma alguma, a de um refinamento progressivo, de uma racionalidade continuamente crescente [...], mas de seus diversos campos de constituição e de validade" (FOUCAULT, 2005, p. 4-5). Assim, são múltiplos os discursos que concorrem, investem e se reformulam para compor o currículo experimental. Tais discursos, ao fazerem referência a urgências, convergem para fixar, ao longo dos momentos históricos, aulas experimentais como artefato fundamental das disciplinas científicas e para decretar modos de relação que sujeitos têm de estabelecer consigo mesmos, com os outros e com o mundo. Afinal, como sugere o projeto iluminista da modernidade, urge a necessidade de se esclarecer, de se iluminar, de se tornar humano.

Um currículo que, ao ser vivido por professores/as e alunos/as, opera para demandar, incitar e produzir sujeitos que pensam, agem e comportam-se segundo os conhecimentos científicos. Um currículo que, por meio de relações de poder-saber, produz sujeitos Homo experimentalis. Por ora, convidam-nos/as a se portarem com racionalidade, responsabilidade, empiria, controle e eficiência. Em outras, engendram-nos/as em fases de desenvolvimento biológico, como representantes do senso comum. Se, por vezes, primam-se por acertos, por conhecimentos científicos, por métodos rígidos, em outras, permitem que tenham concepções prévias, que cometam erros.

Ao fotografarmos cenários sob as mais diversas lentes que produzem imagens de aulas experimentais, poderíamos enxergá-las como pertencentes a diferentes momentos históricos, pois cada uma das imagens costuma ser projetada num espaço-tempo, a depender dos discursos que a produziram e produzem. Porém, vimos que, por meio de tal ensaio fotográfico, todas as imagens ainda existem hoje, delineadas pelas abordagens de ensino que fundamentam uma aula. Por isso, não corremos o risco de argumentar que cada abordagem em torno da experimentação ocorre separadamente ou que é influenciada por um ou outro discurso isoladamente, ou que algumas já se extinguiram.

Ao mapearmos tais estudos, objetivamos apontar diferenças, conflitos, disputas, enfim, o empenho dos múltiplos discursos que compõem o currículo experimental. Veiculadora de múltiplos discursos, a literatura especializada aqui analisada sugere, recomenda, critica, desfaz, refaz, ressuscita, reformula, enfim, engendra professores/as, alunos/as e cenários de aulas experimentais. Longe de ter sido um ensaio fotográfico estático e calmo, o território desse currículo foi se constituindo aos rabiscos de conflituosas enunciações. Por meio da técnica de montagem, percebemos que os componentes cenográficos faziam mais sentido misturados do que organizados em cada cenário. Porém, curiosamente, alguns preferem ver este álbum sob lentes que dão foco, nitidez e uniformidade. Aqui, preferimos apreciá-lo como uma astuta montagem de fotografias. 
Álbum fotográfico: um mapa de cenários ...

\section{Referências}

ABEGG, I. Ensino-investigativo de ciências naturais e suas tecnologias nas séries iniciais do ensino fundamental. 2004. 120 f. Dissertação (Mestrado em Educação Científica e Tecnológica) - Universidade Federal de Santa Catarina, Florianópolis, 2004.

ABIB, M. L. V. S.; TESTONI, L. A.; CUNHA, A. M.; Atividades de experimentação e modelagem em estágio investigativo e o desenvolvimento de conhecimentos pedagógicos do conteúdo. In: ENCONTRO NACIONAL DE PESQUISA EM EDUCAÇÃO EM CIÊNCIAS, 8., 2011, Campinas. Atas... Disponível em: <http://www.nutes.ufrj.br/ abrapec/viiienpec/resumos/R1581-1.pdf >. Acesso em: 29 jan. 2014.

ALVES FILHO, J. Atividades experimentais: do método à prática construtivista. $370 \mathrm{f}$. 2000. Tese (Doutorado) - Centro de Ciências da Educação, Universidade Federal de Santa Catarina, Florianópolis, 2000.

ALVES, J. C. N. Uma proposta pedagógica para uso do computador em ambientes de ensino experimental de física. 2000. 295 f. Tese (Doutorado) - Universidade Federal do Rio de Janeiro, Rio de Janeiro, 2000.

ALVES, P. F. P. A experimentação nos livros didáticos de ciências das séries iniciais do ensino fundamental. 2000. 151 f. Dissertação (Mestrado) - Universidade Federal de Uberlândia, Uberlândia, 2000.

AMARAL, M. B. Natureza e representação na pedagogia da publicidade. In: COSTA, M. V. (Org.). Estudos culturais em educação: mídia, arquitetura, brinquedo, biologia, literatura, cinema. Porto Alegre: Ed. Universidade: UFRGS, 2000.

AMON-SANTARELLI, M. C. I., MURAMATSU, M. A importância da afetividade na experimentação em física. In: ENCONTRO NACIONAL DE PESQUISA EM EDUCAÇÃO EM CIÊNCIAS, 8., 2011, Campinas. Atas... Disponível em: <http:// www.nutes.ufrj.br/abrapec/viiienpec/resumos/R1105-2.pdf >. Acesso em: 29 jan. 2014.

ARAÚJO, A. O.; MORTIMER, E. F. As práticas epistêmicas e suas relações com os tipos de texto que circulam em aulas práticas de química. In: ENCONTRO NACIONAL DE PESQUISA EM EDUCAÇÃO EM CIÊNCIAS, 7, 2009, Florianópolis. Atas... Disponível em: < http://posgrad.fae.ufmg.br/posgrad/viienpec/pdfs/1009.pdf >. Acesso em: 29 jan. 2014.

ARAÚJO, M. P. et al. As atividades experimentais como proposta na abordagem contextualizada dos conteúdos de biologia. In: ENCONTRO NACIONAL DE PESQUISA EM EDUCAÇÃO EM CIÊNCIAS, 8., 2011, Campinas. Atas... Disponível em: < http://www.nutes.ufrj.br/abrapec/viiienpec/resumos/R1386-1.pdf > . Acesso em: 29 jan. 2014.

ARAUJO, N. R. S. Categorias para a seleção de experimentos de química no ensino médio. 2007. 183 f. Dissertação (Mestrado em Ensino de Ciências e Educação Matemática) - Centro de Ciências Exatas, Universidade Estadual de Londrina, 2007. 
ARISTÓTELES. Metafísica. In: SELEÇÃO de textos de José Américo Motta Pessanha. Trad. Vincenzo Cocco. São Paulo: Abril Cultural, 1984a.

ARISTÓTELES. Ética à Nicômico. In: SELEÇÃO de textos de José Américo Motta Pessanha. Trad. Leonel Vallandro e Gerd Bornheim. São Paulo: Abril Cultural, 1984b.

ARRUDA, S. de M.; SILVA, M. R.; LABURÚ, C. E. Laboratório didático de física a partir de uma perspectiva kuhniana. Investigações em Ensino de Ciências, Porto Alegre, v. 6, n. 1, p. 97-106, 2001. Disponível em: < http://www.if.ufrgs.br/ienci/artigos/Artigo_ID70/ v6_n1_a2001.pdf>. Acesso em: 29 jan. 2014.

ASSIS, A.; LABURÚ, C. A seleção de experimentos de química pelo professor. Revista Brasileira de Pesquisa em Educação em Ciências, Belo Horizonte, v. 9, n. 1, 2009

ATAÍDE, M. C. E. S.; DANTAS, J. M.; SILVA, M. G. L. Experimentos que geram rejeitos químicos: uma discussão à luz dos livros didáticos. In: ENCONTRO NACIONAL DE PESQUISA EM EDUCAÇÃO EM CIÊNCIAS, 7, 2009, Florianópolis. Atas... Disponível em: < http://posgrad.fae.ufmg.br/posgrad/viienpec/pdfs/652.pdf >. Acesso em: 29 jan. 2014.

AZEVEDO, M. C. P. S. Ensino por investigação: problematizando as atividades em sala de aula. In: CARVALHO, A. (Org.). Ensino de ciências: unindo a pesquisa e a prática. São Paulo: Pioneira, 2004. p. 19-33.

BACON, F. Novum organum: aforismo XIX. São Paulo: Abril, 1988.

BARATIERI, S. M. A experimentação no ensino de química: uma pesquisa com alunos do ensino médio. 2004. 105 f. Dissertação (Mestrado em Educação em Ciências e Matemática) - Pontifícia Universidade Católica, Porto Alegre, 2004.

BARBERÁ, O.; VALDÉS, P. El trabajo práctico en la enseñanza de las ciencias: una revisión. Enseñanza de las Ciencias, Barcelona, v. 14, n. 3, p. 365-379, 1996.

BARBIERI, C. V. Atividades experimentais de química: reconstruindo a argumentação na educação pela pesquisa. 2004. 163 f. Dissertação (Mestrado em Educação em Ciências e Matemática) - Pontifícia Universidade Católica, Porto Alegre, 2004.

BEZERRA JR. et al. Atividades experimentais de física mediadas por videoanálise e o software livre Tracker na formação. In: ENCONTRO NACIONAL DE PESQUISA EM EDUCAÇÃO EM CIÊNCIAS, 8., 2011, Campinas. Atas... Disponível em: <http:// www.nutes.ufrj.br/abrapec/viiienpec/resumos/R0565-1.pdf >. Acesso em: 29 jan. 2014.

BINSFELD, S. C.; AUTH, M. A. A experimentação no ensino de ciências da educação básica: constatações e desafios. In: ENCONTRO NACIONAL DE PESQUISA EM EDUCAÇÃO EM CIÊNCIAS, 8., 2011, Campinas. Atas... Disponível em: <http:// www.nutes.ufrj.br/abrapec/viiienpec/resumos/R1382-1.pdf >. Acesso em: 29 jan. 2014. 
Álbum fotográfico: um mapa de cenários ...

BONATTO, M. et al. Iniciação a química no museu da vida, Fiocruz: avaliando atividades experimentais interativas da bancada de Pasteur. In: ENCONTRO NACIONAL DE PESQUISA EM EDUCAÇÃO EM CIÊNCIAS, 7, 2009, Florianópolis. Atas... Disponível em: <http://posgrad.fae.ufmg.br/posgrad/viienpec/pdfs/1606.pdf>. Acesso em: 29 jan. 2014.

BORGES, A. T. Novos rumos para o laboratório escolar de ciências. Caderno Brasileiro de Ensino de Física, Florianópolis, v. 19, n. 3, p. 291-313, 2002.

BOSS, S. L. B.; SOUZA FILHO, M. P.; CALUZI, J. J. História da ciência e aprendizagem significativa: o experimento de Coulomb. In: ENCONTRO NACIONAL DE PESQUISA EM EDUCAÇÃO EM CIÊNCIAS, 7, 2009, Florianópolis. Atas... Disponível em: <http:// posgrad.fae.ufmg.br/posgrad/viienpec/pdfs/1567.pdf >. Acesso em: 29 jan. 2014.

CALUZI, J. J.; SOUZA FILHO, M. P.; BOSS, S. L. B. A história hipotética na física: distorsões da história da ciência nos livros didáticos sobre o experimento de Oersted. In: ENCONTRO NACIONAL DE PESQUISA EM EDUCAÇÃO EM CIÊNCIAS, 6, 2007, Florianópolis. Atas... Disponível em: <http://www.nutes.ufrj.br/abrapec/vienpec/CR2/ p1060.pdf>. Acesso em: 29 jan. 2014.

CAMPOS, L. da S.; ARAÚJO, M. S. A modelagem matemática e a experimentação aplicadas ao ensino de física. In: ENCONTRO NACIONAL DE PESQUISA EM EDUCAÇÃO EM CIÊNCIAS, 7, 2009, Florianópolis. Atas... Disponível em: <http:// posgrad.fae.ufmg.br/posgrad/viienpec/pdfs/1753.pdf >. Acesso em: 29 jan. 2014.

CAMPOS, L. S.; ARAÚJO, M. S. T. Articulação entre o ensino de matemática e de física: uma aproximação entre a modelagem matemática e as atividades experimentais. In: ENCONTRO NACIONAL DE PESQUISA EM EDUCAÇÃO EM CIÊNCIAS, 8., 2011, Campinas. Atas... Disponível em: < http://www.nutes.ufrj.br/abrapec/viiienpec/resumos/ R0013-1.pdf >. Acesso em: 29 jan. 2014.

CAPECHI, M. C. V. de M. Aspectos da cultura científica em atividades de experimentação nas aulas de física. 2004. 263 f. Tese (Doutorado) - Faculdade de Educação, Universidade de São Paulo, São Paulo, 2004.

CARDOSO, A. M.; SUART, R. C. Análise da prática pedagógica de professoras de química em atividades experimentais no ensino médio. In: ENCONTRO NACIONAL DE PESQUISA EM EDUCAÇÃO EM CIÊNCIAS, 8., 2011, Campinas. Atas... Disponível em: < http://www.nutes.ufrj.br/abrapec/viiienpec/resumos/R0487-1.pdf > . Acesso em: 29 jan. 2014.

CARDOSO, L. R. Processos de recontextualização no ensino de ciências da escola do campo: a visão dos professores do sertão sergipano. 2009. 179 f. Dissertação (Mestrado em Educação) - Universidade Federal de Sergipe, São Cristovão, 2009.

CARDOSO, L. R. Um encantado governo do certo-errado: posições de sujeito no currículo de aulas experimentais de ciências. In: ENCONTRO NACIONAL DE PESQUISA EM EDUCAÇÃO EM CIÊNCIAS, 8., 2011, Campinas. Atas... Disponível em: <http:// www.nutes.ufrj.br/abrapec/viiienpec/resumos/R0262-2.pdf>. Acesso em: 29 jan. 2014. 
CARDOSO, L. R.; OLIVEIRA, V. S. O uso das tecnologias da comunicação digital: desafios no ensino de genética mendeliana no ensino médio. Informática na Educação: teoria e prática, Porto Alegre, v. 13, n. 1, p. 101-114, 2010.

CARNEIRO, M. F. D.; OLIVEIRA, L. M. L. P. A abordagem histórica do experimento da dispersão da luz branca em livros didáticos. In: ENCONTRO NACIONAL DE PESQUISA EM EDUCAÇÃO EM CIÊNCIAS, 8., 2011, Campinas. Atas... Disponível em: <http://www.nutes.ufrj.br/abrapec/viiienpec/resumos/R0620-1.pdf >. Acesso em: 29 jan. 2014.

CARVALHO, A. M. P. et al. Ciências no ensino fundamental: o conhecimento físico. São Paulo: Scipione, 1998.

CASAGRANDE, E. O papel da experimentação no estudo do solo através do ensino de química: relações entre ensino e aprendizagem. 2006. Dissertação (Mestrado em Educação Agrícola) - Universidade Federal Rural do Rio de Janeiro, Seropédica, 2006.

CHALMERS, A. A fabricação da ciência. São Paulo: Editora UNESP, 1994.

CHASSOT, A. Alfabetização científica: uma possibilidade para a inclusão social. Revista Brasileira de Educação, Rio de Janeiro, n. 22, p. 89-100, 2003.

DAVID, M.; BORGES, O. Uma abordagem teórica para coleta de dados cognitivos durante a realização de um experimento de química. In: ENCONTRO NACIONAL DE PESQUISA EM EDUCAÇÃO EM CIÊNCIAS, 6, 2007, Florianópolis. Atas... Disponível em: <http://www.nutes.ufrj.br/abrapec/vienpec/CR2/p1083.pdf >. Acesso em: 29 jan. 2014.

DEBOER, G. E. Historical perspectives on inquiry in school. In: FLICK, L. B.; LIDERMAN, N. G. Scientific inquiry and nature of science: implications for teching, learning and teacher education. New York: Springer, 2006. p. 17-37.

DEWEY, J. Como pensamos: como se relaciona o pensamento reflexivo com o processo educativo, uma reexposição. São Paulo: Companhia Editora Nacional, 1959.

DINIZ, R. E. A experimentação e o ensino de ciências no primeiro grau: analisando a experimentoteca de sétima série. 1992. 227 f. Dissertação (Mestrado) - Centro de Educação e Ciências Humanas, Universidade Federal de São Carlos, São Carlos, 1992.

FEITAS. J. F. O experimento da vela na formação inicial do professor de ciências. In: ENCONTRO NACIONAL DE PESQUISA EM EDUCAÇÃO EM CIÊNCIAS, 8., 2011, Campinas. Atas... Disponível em: <http://www.nutes.ufrj.br/abrapec/viiienpec/resumos/ R0795-1.pdf >. Acesso em: 29 jan. 2014.

FERNANDES, M. M.; SILVA, M. H. S. O trabalho experimental de investigação. Revista Brasileira de Pesquisa em Educação em Ciências, Belo Horizonte, v. 4, n. 1, p. 45-58, 2004.

FERREIRA, M. S. Investigando os rumos da disciplina escolar ciências no Colégio Pedro II: 1960-1970. Educação em Revista, Belo Horizonte, n. 45, p. 127-144, 2007. 
Álbum fotográfico: um mapa de cenários ...

FIRME, M. V. F., GALIAZZI, M. C. A aula experimental registrada em portfólios coletivos: a formação potencializada pela integração entre licenciandos e professores da escola básica. In: ENCONTRO NACIONAL DE PESQUISA EM EDUCAÇÃO EM CIÊNCIAS, 8., 2011, Campinas. Atas... Disponível em: < http://www.nutes.ufrj.br/ abrapec/viiienpec/resumos/R1137-1.pdf >. Acesso em: 29 jan. 2014.

FISHER, R. Foucault e análise do discurso em educação. Cadernos de Pesquisa, São Paulo, n. 114, p. 197-223, 2001.

FOUCAULT, M. A arqueologia do saber. Rio de Janeiro: Forense Universitária, 2005.

FOUCAUlT, M. A ordem do discurso. São Paulo: Loyola, 2009.

FOUCAULT, M. A verdade e as formas jurídicas. 3. ed. Rio de Janeiro: NAU, 2003.

FOUCAULT, M. Poder e saber. In: MOTTA, M. B. da (Org.). Estratégias, poder-saber. 2. ed. Rio de Janeiro: Forense Universitária, 2006. p. 223-240.

FOUCAULT, M. Verdade e poder. In: MACHADO, R. (Org.). Microfísica do poder. 24. ed. Rio de Janeiro: Graal, 2007. p. 1-14.

FOUREZ, G. A construção das ciências: introdução à filosofia e ética das ciências. São Paulo: Editora da UNESP, 1995.

FRANCISCO, W.; FRANCISCO JUNIOR, W. E. Leitura e experimentação com o auxílio de recursos audiovisuais: reflexões sobre a manifestação de habilidades cognitivas e considerações para o ensino. In: ENCONTRO NACIONAL DE PESQUISA EM EDUCAÇÃO EM CIÊNCIAS, 8., 2011, Campinas. Atas... Disponível em: <http:// www.nutes.ufrj.br/abrapec/viiienpec/resumos/R0919-1.pdf >. Acesso em: 29 jan. 2014.

GALIAZZI, M. C. et al. Objetivos das atividades experimentais no ensino médio: a pesquisa coletiva como modo de formação de professores de ciências. Ciência \& Educação, Bauru, v. 7, n. 2, p. 249-263, p. 2001.

GARDELLI, D.; NEVES, M.C. D. Equívocos encontrados nos livros didáticos de física no ensino médio sobre a interpretação dada à experiência de Oersted. In: ENCONTRO NACIONAL DE PESQUISA EM EDUCAÇÃO EM CIÊNCIAS, 8., 2011, Campinas. Atas... Disponível em: <http://www.nutes.ufrj.br/abrapec/viiienpec/resumos/R11511.pdf >. Acesso em: 29 jan. 2014.

GASPAR, A.; MONTEIRO, I. C. Atividades experimentais de demonstrações em sala de aula: uma análise segundo o referencial da teoria de Vygotsky. Investigações em Ensino de Ciências, Porto Alegre, v. 10. n. 2, p. 227-254, 2005.

GIOPPO, C.; SCHEFFER, E. W. O.; NEVES, M. C. D. O ensino experimental na escola fundamental: uma reflexão de caso no Paraná. Educar, Curitiba, n. 14, p. 39-57, 1998.

GIORDAN, M. O papel da experimentação no ensino de ciências. Química Nova na Escola, São Paulo, n. 10, p. 43-49, 1999. 
GOMES, A. D. T.; BORGES, A. T.; JUSTI, R. Processos e conhecimentos envolvidos na realização de atividades práticas. Investigações em Ensino de Ciências, Porto Alegre, v. 13, n. 2, p. 187-207, 2008.

GONÇALVES, F. P.; MARQUES, C. A. A problematização das atividades experimentais na formação inicial de professores de química: uma pesquisa com formadores. In:

ENCONTRO NACIONAL DE PESQUISA EM EDUCAÇÃO EM CIÊNCIAS, 8., 2011, Campinas. Atas... Disponível em: <http://www.nutes.ufrj.br/abrapec/viiienpec/resumos/ R1268-1.pdf >. Acesso em: 29 jan. 2014.

GONÇALVES, F. P.; MARQUES, C. A. Contribuições pedagógicas e epistemológicas em textos de experimentação no ensino de química. Investigações em Ensino de Ciências, Porto Alegre, v. 11, n. 2, p. 219-238, 2006.

GONDIM, M. S. da C.; MOL, G. de S. Experimentos investigativos em laboratório de química fundamental. In: ENCONTRO NACIONAL DE PESQUISA EM EDUCAÇÃO EM CIÊNCIAS, 6, 2007, Florianópolis. Atas... Disponível em: <http://www.nutes.ufrj.br/ abrapec/vienpec/CR2/p720.pdf >. Acesso em: 29 jan. 2014.

GOODSON, I. Currículo: teoria e história. Petrópolis: Vozes, 1995.

GOUVEIA, M. S. F. Atividades de ciências: a relação teoria-prática no ensino. Ensino em Re-vista, Uberlândia, v. 3, n. 1, p. 9-14, 1994.

GUEDES, S. S., BAPTISTA, J.A. Experimentação no ensino de ciências: atividades problematizadas e interações dialógicas. In: ENCONTRO NACIONAL DE PESQUISA EM EDUCAÇÃO EM CIÊNCIAS, 8., 2011, Campinas. Atas... Disponível em: <http:// www.nutes.ufrj.br/abrapec/viiienpec/resumos/R0319-1.pdf >. Acesso em: 29 jan. 2014.

GÜLLICH, R. I. C.; SILVA, L. H. A. O enredo da experimentação no livro didático: reprodução de teorias e verdades científicas. In: ENCONTRO NACIONAL DE PESQUISA EM EDUCAÇÃO EM CIÊNCIAS, 8., 2011, Campinas. Atas... Disponível em: <http:// www.nutes.ufrj.br/abrapec/viiienpec/resumos/R0755-2.pdf >. Acesso em: 29 jan. 2014.

HALL, S. A identidade cultural na pós-modernidade. 6. ed. Rio de Janeiro: DP\&A, 2001.

HERNANDES, C. L. Atividades experimentais no ensino da física moder na e a prática pedagógica de professores. 2002. 200 f. Dissertação (Mestrado em Educação) Universidade Federal de Santa Maria, Santa Maria, 2002.

HIGA, I. Atividades experimentais significativas no ensino de física: aplicação à óptica. 1997. 105 f. Dissertação (Mestrado) - Instituto de Física, Universidade de São Paulo, São Paulo, 1997

HOERNIG, A.; PEREIRA, A. B. As aulas de ciências iniciando pela prática: o que pensam os alunos. Revista Brasileira de Pesquisa em Educação em Ciências, São Paulo, v. 4, n. 3., p. 19-29, 2004. Disponível em: <http://revistas.if.usp.br/rbpec/article/viewFile/102/ 94>. Acesso em: 28 jan. 2014. 
Álbum fotográfico: um mapa de cenários ...

HUME, D. O tratado da natureza humana: uma tentativa de introduzir o método experimental de raciocínio nos assuntos morais. São Paulo: UNESP, 2009.

JAPIASSU, H. Como nasceu a ciência moderna: e as razões da filosofia. Rio de Janeiro: Imago, 2007.

KANBACH, B. G. A relação com o saber profissional e o emprego de atividades experimentais em física no ensino médio: uma leitura baseada em Bernard Charlot. Dissertação (Mestrado em Ensino de Ciências e Educação Matemática) - Universidade Estadual de Londrina, Londrina, 2005.

KRASILCHIK, M. Ensino de ciências e a formação do cidadão. Em Aberto, Brasília, v. 7, n. 40, p. 55-60, 1988.

KRASILCHIK, M. O professor e o currículo das ciências. São Paulo: Edusp, 1987.

KRASILCHIK, M.; MARANDINO, M. Ensino de ciências e cidadania. São Paulo: Moderna, 2004.

LABURÚ, C. E. Seleção de experimentos de física no ensino médio: uma investigação a partir da fala de professores. Investigações em Ensino de Ciências, Porto Alegre, v. 10, n. 2, p. 161-178, 2005.

LABURÚ, C.; BARROS, M.; KANBACHI, B. A relação com o saber profissional do professor de física e o fracasso da implementação de atividades experimentais.

Investigações em Ensino de Ciências, Porto Alegre, v. 12, n. 3, p. 305-320, 2007.

LACEY, H. Valores e atividades científicas. São Paulo: Discurso Editorial, 1998.

LAJONQUIÈRE, L. Infância e ilusão (psico)pedagógica: escritos de psicanálise e educação. 4. ed. Petrópolis: Vozes, 2009.

LATINI, R. M.; CANESIN, F. P.; COTELO, P. F. S. M. Roteiro de atividades experimentais como instrumento de inserção de novas metodologias no ensino de química. In:

ENCONTRO NACIONAL DE PESQUISA EM EDUCAÇÃO EM CIÊNCIAS, 8., 2011, Campinas. Atas... Disponível em: <http://www.nutes.ufrj.br/abrapec/viiienpec/resumos/ R0498-2.pdf >. Acesso em: 29 jan. 2014.

LATOUR, B.; WOOLGAR, S. A vida de laboratório: a produção dos fatos científicos. Rio de Janeiro: Relume Dumará, 1997.

LIBARDONI, G. C.: SAUERWEIN, R. A.; ALVES, J. Inserção de novas tecnologias em conjunto com aulas experimentais da cinemática: MRU e MRUV. In: ENCONTRO

NACIONAL DE PESQUISA EM EDUCAÇÃO EM CIÊNCIAS, 8., 2011, Campinas.

Atas... Disponível em: <http://www.nutes.ufrj.br/abrapec/viiienpec/resumos/R01051.pdf >. Acesso em: 29 jan. 2014.

LIMA, V. A. de. Atividades experimentais no ensino médio: reflexão de um grupo de professores a partir do tema eletroquímica. 2004. 215 f. Dissertação (Mestrado) - Instituto de Química, Universidade de São Paulo, São Paulo, 2004. 
Cardoso, L. R.; Paraíso, M. A.

LIMA, V. A., MARCONDES, M. E. R. O ensino experimental como ferramenta no processo reflexivo dos professores de química. In: ENCONTRO NACIONAL DE PESQUISA EM EDUCAÇÃO EM CIÊNCIAS, 8., 2011, Campinas. Atas... Disponível em: <http://www.nutes.ufrj.br/abrapec/viiienpec/resumos/R0427-1.pdf >. Acesso em: 29 jan. 2014.

LÜDKE, M. O professor, seu saber e sua pesquisa. Educação \& Sociedade, Campinas, v. 22, n. 74, p. 77-96, 2001.

MACEDO, E. Ciência, tecnologia e desenvolvimento: uma visão cultural do currículo de Ciências. In: __ ( O (Org). Currículo de ciências em debate. Campinas: Papirus, 2004. p. $119-152$.

MALHEIRO, J. M. S. A resolução de problemas de biologia com base em atividades experimentais investigativas: uma análise das habilidades cognitivas presentes em alunos do ensino médio durante um curso de férias. In: ENCONTRO NACIONAL DE PESQUISA EM EDUCAÇÃO EM CIÊNCIAS, 8., 2011, Campinas. Atas... Disponível em: < http:// www.nutes.ufrj.br/abrapec/viiienpec/resumos/R0280-2.pdf>. Acesso em: 29 jan. 2014.

MAMPRIN, M. I. L. L. Implementação ou não de atividades experimentais em biologia no ensino médio: as relações com o saber profissional baseadas numa leitura de Charlot. 2007. 178 f. Dissertação (Mestrado) - Universidade Estadual de Londrina, Londrina, 2007.

MAMPRIN, M. I. L. L.; LABURÚ, C. E.; BARROS, M. A. A implementação ou não de atividades experimentais em biologia no ensino médio e as relações com o saber profissional, baseadas numa leitura de Charlot. In: ENCONTRO NACIONAL DE PESQUISA EM EDUCAÇÃO EM CIÊNCIAS, 6, 2007, Florianópolis. Atas... Disponível em: <http:// www.nutes.ufrj.br/abrapec/vienpec/CR2/p43.pdf >. Acesso em: 29 jan. 2014.

MARCHEZINI, R. Uso de aulas experimentais: mudanças conceituais no ensino de momento de uma força. 2008. 131 f. Dissertação (Mestrado em Ensino de Ciências e Matemática) - Pontifícia Universidade Católica, Belo Horizonte, 2008.

MARTINS, L. A. P. A história da ciência e o ensino da biologia. Ciência \& Ensino, Campinas, n. 5, p. 18-21, 1998.

MARTINS, M. C. De carne e espírito: a educação pelas coisas e objetos. In: CONGRESSO IBEROAMERICANO DE HISTÓRIA DA EDUCAÇÃO LATINO-AMERICANA, 9., 2009, Fortaleza. Anais... Fortaleza: Itarget Tecnologia de Informação, 2009. v. 1, p. 1-9.

MARUYAMA, U., BRAGA, M., GUERRA, A. Leis \& teorias: identificando aspectos sobre visões de natureza da ciência em estudantes do ensino médio num curso de física experimental. In: ENCONTRO NACIONAL DE PESQUISA EM EDUCAÇÃO EM CIÊNCIAS, 8., 2011, Campinas. Atas... Disponível em: < http://www.nutes.ufrj.br/abrapec/ viiienpec/resumos/R0257-1.pdf > . Acesso em: 29 jan. 2014.

MATOS, M. G.; VALADARES, J. O efeito da atividade experimental na aprendizagem da ciência pelas crianças do primeiro ciclo do ensino básico. Investigações em Ensino de 
Álbum fotográfico: um mapa de cenários ...

Ciências, Porto Alegre, v. 6, n. 2, p. 227-239, 2001.

MERAZZI, D. W.; OAIGEN, E. R. Atividades práticas do cotidiano e o ensino de ciências na EJA: a percepção de educandos e docentes. In: ENCONTRO NACIONAL DE PESQUISA EM EDUCAÇÃO EM CIÊNCIAS, 7, 2009, Florianópolis. Atas... Disponível em: <http://www.ppgecm.ufpa.br/revistaamazonia/vol_03/v03_p01.pdf > . Acesso em: 29 jan. 2014.

MIQUELIN, A. F. Ensino-investigativo de física: trabalhando numa abordagem sistêmica em ambiente multimídia-telemático. 2003. 125 f. Dissertação (Mestrado) - Centro de Educação, Universidade Federal de Santa Maria, Santa Maria, 2003.

MONTEIRO JÚNIOR, F.; CALUZI, J.; CARVALHO, W. O aparato de Lissajous e o ensino experimental das vibrações mecânicas. In: ENCONTRO NACIONAL DE PESQUISA EM EDUCAÇÃO EM CIÊNCIAS, 7, 2009, Florianópolis. Atas... Disponível em: < http://posgrad.fae.ufmg.br/posgrad/viienpec/pdfs/349.pdf >. Acesso em: 29 jan. 2014.

MONTEIRO, I. C. C. Atividades experimentais de demonstração em sala de aula: uma análise segundo o referencial da teoria de Vygotsky. Investigações em Ensino de Ciências, Porto Alegre, v. 10, n. 2, p. 227-254, ago. 2005.

MORAES, R. O significado de experimentação numa abordagem construtivista: o caso do ensino de ciências. In: BORGES, R. M. R.; MORAES, R. Educação em ciências nas séries iniciais. Porto Alegre: Sagra Luzzatto, 1998. p. 29-45.

MOREIRA, E. F. Ensino por investigação: ensinando e aprendendo a cultura da ciência. 2005. 121 f. Dissertação (Mestrado) - Faculdade de Educação, Universidade de São Paulo, São Paulo, 2005.

MOREIRA, W. A.; TRENTIN, P. H.; FERNANDEZ, C. O experimento da vela encapsulada e a argumentação: uma investigação com base no modelo argumentativo de Toulmin. In: ENCONTRO NACIONAL DE PESQUISA EM EDUCAÇÃO EM CIÊNCIAS, 8., 2011, Campinas. Atas... Disponível em: < http://www.nutes.ufrj.br/ abrapec/viiienpec/resumos/R0343-1.pdf>. Acesso em: 29 jan. 2014.

MORRONE, W.; ARAÚJO, M. S. T.; AMARAL, L. H. Analogias e experimentação em eletrodinâmica baseadas no conhecimento sensível: um experimento para aprendizagem significativa de alunos deficientes visuais. In: ENCONTRO NACIONAL DE PESQUISA EM EDUCAÇÃO EM CIÊNCIAS, 7, 2009, Florianópolis. Atas... Disponível em: <http:// posgrad.fae.ufmg.br/posgrad/viienpec/pdfs/115.pdf >. Acesso em: 29 jan. 2014.

MOURA, G. N.; CHAVES, S. N. Encontros e desencontros com a experimentação no ensino de ciências. In: ENCONTRO NACIONAL DE PESQUISA EM EDUCAÇÃO EM CIÊNCIAS, 8., 2011, Campinas. Atas... Disponível em: < http://www.nutes.ufrj.br/ abrapec/viiienpec/resumos/R0041-1.pdf >. Acesso em: 29 jan. 2014.

MOURA, G. N.; CHAVES, S. N. Visões e virtudes pedagógicas do ensino experimental da química. In: ENCONTRO NACIONAL DE PESQUISA EM EDUCAÇÃO EM 
CIÊNCIAS, 7, 2009, Florianópolis. Atas... Disponível em: <http://posgrad.fae.ufmg.br/ posgrad/viienpec/pdfs/628.pdf >. Acesso em: 29 jan. 2014.

MUNAKATA, K. Que coisa é coisa da lição de coisas?. In: CONGRESSO IBEROAMERICANO DE HISTÓRIA DA EDUCAÇÃO LATINO-AMERICANA, 9., 2009, Fortaleza. Anais... Rio de Janeiro: Quartet, 2009. p. 203-204.

NASCIMENTO, T. G. Leituras de divulgação científica na formação inicial de professores de ciências. 2008. 376 f. Tese (Doutorado) - Centro de Ciências Físicas e Matemáticas, Universidade Federal de Santa Catarina, Florianópolis, 2008.

NEHRING, C. M. et al. As ilhas de racionalidade e o saber significativo: o ensino de ciências através de projetos. Ensaio: pesquisa em educação em ciências, Belo Horizonte, v. 2, n. 1, p. 99-122, 2000. Disponível em: < http://www.portal.fae.ufmg.br/seer/index.php/ ensaio/article/view/17/47>. Acesso em: 03 fev. 2014.

NIEZER, T. M.; SILVEIRA, R. M. C. F.; SAUER, E. Atividades experimentais no ensino de química, avaliando as propriedades físico-químicas do leite: uma abordagem CTS. In: ENCONTRO NACIONAL DE PESQUISA EM EDUCAÇÃO EM CIÊNCIAS, 8., 2011, Campinas. Atas... Disponível em: <http://www.nutes.ufrj.br/abrapec/viiienpec/resumos/ R0655-1.pdf >. Acesso em: 29 jan. 2014.

OLIVEIRA, K. B; ARAUJO, M. F. F.; PRADO, M. R. M. Limites e possibilidades da utilização de atividades experimentais como instrumento didático em escolas públicas do Rio Grande do Norte-Brasil. In: ENCONTRO NACIONAL DE PESQUISA EM EDUCAÇÃO EM CIÊNCIAS, 8., 2011, Campinas. Atas... Disponível em: <http:// www.nutes.ufrj.br/abrapec/viiienpec/resumos/R0408-1.pdf >. Acesso em: 29 jan. 2014.

OLIVEIRA, M. B. Da ciência cognitiva à dialética. São Paulo: Discurso Editorial, 1999.

OLIVEIRA, M. A. de. Enunciados científicos nos laboratórios de ciências do ensino médio. 2005. Tese (Doutorado em Educação) - Universidade do Vale do Rio dos Sinos, São Leopoldo, 2005.

OZÓRIO, T. M. A.; FERREIRA, F. C.; SILVA, L. H. A. Experimentos e demonstrações de física como instrumento da prática pedagógica no ensino de ciências. In: ENCONTRO NACIONAL DE PESQUISA EM EDUCAÇÃO EM CIÊNCIAS, 7, 2009, Florianópolis. Atas... Disponível em: <http://posgrad.fae.ufmg.br/posgrad/viienpec/pdfs/1189.pdf >. Acesso em: 29 jan. 2014.

PARAÍSO, M. A. Currículo-mapa: linhas e traçados das pesquisas pós-críticas sobre o currículo e no Brasil. In: REUNIÃO ANUAL DA ANPED 26., 2003, Poços de Caldas. Anais... Disponível em: <http:/ /26reuniao.anped.org.br/trabalhos/ marlucyalvesparaiso.rtf>. Acesso em: 30 jan. 2014.

PARAÍSO, M. A. Política da subjetividade docente no currículo da mídia educativa brasileira. Educação e Sociedade, Campinas, v. 27, n. 94, p. 91-115, 2006. 
Álbum fotográfico: um mapa de cenários ...

PEDROSO, C. V.; ROSA, R. T. N.; AMORIM, M. A. L. Reflexões e perspectivas a respeito das atividades experimentais de genética propostas em livros didáticos de Biologia. In: ENCONTRO NACIONAL DE PESQUISA EM EDUCAÇÃO EM CIÊNCIAS, 7, 2009, Florianópolis. Atas... Disponível em: <http://posgrad.fae.ufmg.br/posgrad/ viienpec/pdfs/406.pdf >. Acesso em: 29 jan. 2014.

PENA, F. L. A.; RIBEIRO FILHO, A. Obstáculos para o uso da experimentação no ensino de física: um estudo a partir de relatos de experiências pedagógicas brasileiras publicados em periódicos nacionais da área (1971-2006). Revista Brasileira de Pesquisa em Educação em Ciências, Belo Horizonte, v. 9, n. 1, p. 1-13, 2009. Disponível em: < http:// revistas.if.usp.br/rbpec/article/download/37/33ý> . Acesso em: 28 jan. 2014.

PEREIRA, G. R. Do lúdico ao científico: construção e avaliação de módulos experimentais de óptica em museus de ciências e em ambientes escolares. 2007. $166 \mathrm{f}$. Dissertação (Mestrado) - Fundação Oswaldo Cruz, Rio de Janeiro, 2007.

PERRENOUD, P. Construir competências desde a escola. Porto Alegre: Artmed, 1998. PIAGET, J. Ensaio de lógica operatória. São Paulo: Globo: Edusp, 1976.

PIAGET, J. Psicologia e pedagogia: a resposta do grande psicólogo aos problemas do ensino. São Paulo: Forense, 1969.

PINO, A. O biológico e o cultural nos processos cognitivos. In: MORTIMER, E. F; SMOLKA, A. L. B. Linguagem, cultura e cognição: reflexões para o ensino e a sala de aula. Belo Horizonte: Autêntica, 2001. p. 21-50.

POPKEWITZ, T. S. Lutando em defesa da alma: a política do ensino e a construção do professor. Porto Alegre: Artmed, 2001.

POPKEWITZ, T. S. Reforma educacional e construtivismo. In: SILVA, T. T. da.

Liberdades reguladas: a pedagogia construtivista e outras formas de governo do eu. Petrópolis: Vozes, 1998. p. 95-142.

PORTO, F. S. et al. Experimentação como estratégia para o ensino de ciências: reflexões sobre a formação inicial de professores a partir de um projeto no laboratório. In: ENCONTRO NACIONAL DE PESQUISA EM EDUCAÇÃO EM CIÊNCIAS, 8., 2011, Campinas. Atas... Disponível em: <http://www.nutes.ufrj.br/abrapec/viiienpec/resumos/ R0220-1.pdf >. Acesso em: 29 jan. 2014.

PRAIA, J.; CACHAPUZ, A.; GIL-PÉREZ, D. A hipótese e a experiência científica em educação em ciência: contributos para uma reorientação epistemológica. Ciência $\boldsymbol{\&}$ Educação, Bauru, v. 8, n. 2, p. 253-262, 2002. Disponível em: <http://www.scielo.br/pdf/ ciedu/v8n2/09.pdf>. Acesso em: 29 jan. 2014.

RAMOS, L.; ROCHA, P. O ensino de ciências: fatores intrínsecos e extrínsecos que limitam a realização de atividades experimentais pelo professor. Investigações em Ensino de 
Cardoso, L. R.; Paraíso, M. A.

Ciências, Porto Alegre, v. 13, n. 3, p. 299-331, 2008.

ROSA, C. W.; ALVES FILHO, J. P. Ensino de física e metacognição: proposta didática para as atividades experimentais. In: ENCONTRO NACIONAL DE PESQUISA EM EDUCAÇÃO EM CIÊNCIAS, 8., 2011, Campinas. Atas... Disponível em: <http:// www.nutes.ufrj.br/abrapec/viiienpec/resumos/R0883-1.pdf >. Acesso em: 29 jan. 2014.

SÁ, E. F. de. Discursos de professores sobre ensino de ciências por investigação. 2009. 203 f. Tese (Doutorado em Educação) - Universidade Federal de Minas Gerais, Belo Horizonte, 2009.

SÁ, E. F. de. Os propósitos das atividades práticas na visão de alunos e de professores. 2003. 198 f. Dissertação (Mestrado) - Universidade Federal de Minas Gerais, Belo Horizonte, 2003.

SALVADEGO, W. A atividade experimental no ensino de química: uma relação com o saber profissional do professor da escola média. 2007. Dissertação (Mestrado) Universidade Estadual de Londrina, 2007.

SALVADEGO, W.; LABURÚ, C.; BARROS, M. A relação com o saber profissional do professor de química e o fracasso da implementação de atividades experimentais no ensino médio. In: ENCONTRO NACIONAL DE PESQUISA EM EDUCAÇÃO EM CIÊNCIAS, 6, 2007, Florianópolis. Atas... Disponível em: <http://www.nutes.ufrj.br/ abrapec/vienpec/CR2/p77.pdf >. Acesso em: 29 jan. 2014.

SANTANA, J. C.; MEDEIROS, Q. A utilização do uso de novas tecnologias no ensino de ciências. In: SEMINÁRIO NACIONAL DE EDUCAÇÃO PROFISSIONAL E TECNOLÓGICA, 1., 2008, Belo Horizonte. Anais... Disponível em: <http:// www.senept.cefetmg.br/galerias/Arquivos_senept/anais/terca_tema1/ TerxaTema1Artigo14.pdf >. Acesso em: 03 fev. 2014.

SANTANA, L. N.; SALOMÃO, S. R. Formação continuada de professores de ciências atuantes na EJA (Educação de Jovens e Adultos): refletindo sobre a utilização de experimentos. In: ENCONTRO NACIONAL DE PESQUISA EM EDUCAÇÃO EM CIÊNCIAS, 8., 2011, Campinas. Atas... Disponível em: < http://www.nutes.ufrj.br/ abrapec/viiienpec/resumos/R0726-1.pdf >. Acesso em: 29 jan. 2014.

SANTIAGO, J. C. R.; COSTA, I. F.; GUIMARÃES, E. M. A experimentação nos livros didáticos de física do ensino médio e os objetivos da educação. In: ENCONTRO NACIONAL DE PESQUISA EM EDUCAÇÃO EM CIÊNCIAS, 8., 2011, Campinas. Atas... Disponível em: <http://www.nutes.ufrj.br/abrapec/viiienpec/resumos/R14641.pdf >. Acesso em: 29 jan. 2014.

SANTOS, E. I. Atividades experimentais lúdicas e com material de baixo custo: uma experiência com formação continuada de professores de física. 2003. 121 f. Dissertação (Mestrado) - Instituto de Física, Universidade de São Paulo, São Paulo, 2003.

SANTOS, L. H. A biologia tem uma história que não é natural. In: COSTA, M. V. (Org.). 
Álbum fotográfico: um mapa de cenários ...

Estudos culturais em educação. Porto Alegre: Ed. Universidade: UFRGS, 2000. p. 229-256.

SANTOS, L. L. de. Dilemas e perspectivas na relação entre ensino e pesquisa. In: ANDRÉ, M. (Org.). O papel da pesquisa na formação e na prática dos professores. 6. ed. Campinas: Papirus, 2001. p. 11-25.

SARAIVA-NEVES, M.; CABALLERO, C.; MOREIRA, M. A. Repensando o papel do trabalho experimental, na aprendizagem da física em sala de aula - um estudo exploratório. Investigações em Ensino de Ciências, Porto Alegre, v. 11, n. 3, p. 383-401, 2006.

SAVI, A. Galileu fez experimento do plano inclinado? Atividades de investigação escolar em física. In: ENCONTRO NACIONAL DE PESQUISA EM EDUCAÇÃO EM CIÊNCIAS, 6, 2007, Florianópolis. Atas... Disponível em: < http://www.nutes.ufrj.br/ abrapec/vienpec/CR2/p1130.pdf >. Acesso em: 29 jan. 2014.

SCHEIN, Z. P. Estudo didático de um experimento centrado em atividades de produção e aplicação de um objeto técnico: a balança analítica. 2004. 200 f. Dissertação (Mestrado) - Pontifícia Universidade Católica, Porto Alegre, 2004.

SCHÖN, D. A. Educando o profissional reflexivo: um novo design para o ensino e a aprendizagem. Porto Alegre: Artmed, 2000.

SILVA, A. B. da. Alteridade, normalização e subjetivação na escola. 2003. Dissertação (Mestrado em Educação) - Universidade Federal do Rio Grande do Sul, Porto Alegre, 2003.

SILVA, A. M. T. B.; METTRAU, M. B.; BARRETO, M. S. L. O lúdico no processo de ensino-aprendizagem das ciências. Revista Brasileira de Estudos Pedagógicos, Brasília, v. 88, n. 222, p. 445-458, 2007.

SILVA, D. P.; MARCONDES, M. E. R.; AKAHOSHI, L. H. Planejamento de atividades experimentais investigativas e a proposição de questões por um grupo de professores de química. In: ENCONTRO NACIONAL DE PESQUISA EM EDUCAÇÃO EM CIÊNCIAS, 8., 2011, Campinas. Atas... Disponível em: < http://www.nutes.ufrj.br/ abrapec/viiienpec/resumos/R1336-1.pdf>. Acesso em: 29 jan. 2014.

SILVA, F. A. et al. Formação pedagógica na área de ciências nas séries iniciais: atividades de laboratório e experimentais. In: ENCONTRO NACIONAL DE PESQUISA EM EDUCAÇÃO EM CIÊNCIAS, 8., 2011, Campinas. Atas... Disponível em: <http:// www.nutes.ufrj.br/abrapec/viiienpec/resumos/R0290-1.pdf >. Acesso em: 29 jan. 2014.

SILVA, L. E. A. Concepções epistemológicas de professores atuantes em atividades experimentais no curso de licenciatura plena em química da PUCRS. 1999. $130 \mathrm{f}$. Dissertação (Mestrado) - Pontifícia Universidade Católica, Porto Alegre, 1999.

SILVA, R. F. et al. O ensino de biologia e as atividades experimentais: uma aposta motivacional para aprendizagem. In: ENCONTRO NACIONAL DE PESQUISA EM EDUCAÇÃO EM CIÊNCIAS, 8., 2011, Campinas. Atas... Disponível em: <http:// www.nutes.ufrj.br/abrapec/viiienpec/resumos/R1146-1.pdf >. Acesso em: 29 jan. 2014. 
SILVA, T. T. da. Currículo e identidade social: territórios contestados. In: (Org.). Alienígenas na sala de aula. Petrópolis: Vozes, 2008. p. 190-207.

SKINNER, B. F. Tecnologia do ensino. São Paulo: EPU, 1972.

SOUSA, C. M. S. G.; MOREIRA, M. A.; MATHEUS, T. A. M. A resolução de situaçõesproblema experimentais no campo conceitual do eletromagnetismo. Revista da

ABRAPEC, v. 5, n. 3, p. 61-72, 2005. Disponível em: < http:// revistas.if.usp.br/rbpec/ article/view/90/82>. Acesso em: 28 jan. 2014.

SOUZA FILHO, M. P. Livros didáticos de física para o ensino médio: uma análise de conteúdo das práticas de eletricidade e magnetismo. 2004. 133 f. Dissertação (Mestrado) Faculdade de Ciências, Universidade Estadual Paulista, Bauru, 2004.

SOUZA, S. J. Infância e linguagem: Bakhtin, Vygotsky e Benjamin. Campinas: Papirus, 1994.

SUART, R.; MARCONDES, M. Habilidades cognitivas manifestadas por alunos do ensino médio de química em uma atividade experimental. Revista Brasileira de Pesquisa em Educação em Ciências, São Paulo, v. 8, n. 2, p. 1-22, 2008.

SUART, R.; MARCONDES, M.; CARMO, M. Atividades experimentais investigativas: utilizando a energia envolvida nas reações químicas para o desenvolvimento de habilidades cognitivas. In: ENCONTRO NACIONAL DE PESQUISA EM EDUCAÇÃO EM CIÊNCIAS, 7, 2009, Florianópolis. Atas... Disponível em: <http://posgrad.fae.ufmg.br/ posgrad/viienpec/pdfs/220.pdf >. Acesso em: 29 jan. 2014.

TEIXEIRA, P. M. M. A educação científica sob a perspectiva da pedagogia histórico-crítica e do movimento CTS no ensino de ciências. Ciência \& Educação, Bauru, v. 9, n. 2, p. 177190, 2003.

TITONI, M. Um estudo de caso sobre o uso de atividades experimentais na Escola Agrotécnica Federal de Sombrio. 2008. 119 f. Dissertação (Mestrado) - Universidade Federal do Rio Grande do Sul, Porto Alegre, 2008.

TOMELIN, N. B. O ensino de ciência na educação básica: um estudo de caso a partir da concepção da ciência de Bruno Latour. 2003. 106 f. Dissertação (Mestrado em Educação) - Universidade Regional de Blumenau, Blumenau, 2003.

VASNIZI, R. A visão dos professores sobre as atividades experimentais no desenvolvimento de competências em física. 2006. 105 f. Dissertação (Mestrado) Universidade de São Paulo, São Paulo, 2006.

VEIGA-NETO, A. Michel Foucault e os estudos culturais. In: COSTA, M. V. (Org.). Estudos culturais em educação. Porto Alegre: Ed. Universidade: UFRGS, 2000. p. 37-69.

VIEIRA, E.; MEIRELLES, R. M. S.; RODRIGUES, D. C. G.A. O uso de tecnologias no ensino de química: a experiência do laboratório virtual química fácil. In: ENCONTRO NACIONAL DE PESQUISA EM EDUCAÇÃO EM CIÊNCIAS, 8., 2011, Campinas. Atas... Disponível em: <http://www.nutes.ufrj.br/abrapec/viiienpec/resumos/R0468- 
Álbum fotográfico: um mapa de cenários ...

1.pdf >. Acesso em: 29 jan. 2014.

VILLANI, C. E. P.; NASCIMENTO, S. S. A argumentação e o ensino de ciências: uma atividade experimental no laboratório didático de física do ensino médio. Investigações em Ensino de Ciências, Porto Alegre, v. 8, n. 3, p. 187-209, 2003.

VYGOTSKY, L. S. Pensamento e linguagem. São Paulo: Martins Fontes, 2009.

WALKERDINE, V. Uma análise foucaultiana da pedagogia construtivista. In: SILVA, T. T. da. Liberdades reguladas: a pedagogia construtivista e outras formas de governo do eu. Petrópolis: Vozes, 1998. p. 142-216.

WESENDONK, F. S., RODRIGUES, L. Z., TERRAZZAN, E. A. Atividades didáticas experimentais em livros didáticos do PNLD para o ensino de biologia e física. In: ENCONTRO NACIONAL DE PESQUISA EM EDUCAÇÃO EM CIÊNCIAS, 8., 2011, Campinas. Atas... Disponível em: <http://www.nutes.ufrj.br/abrapec/viiienpec/resumos/ R1670-1.pdf >. Acesso em: 29 jan. 2014.

WOODWARD, K. Identidade e diferença: introdução teórica e conceitual. In: SILVA, T. T. da (Org.). Identidade e diferença: a perspectiva dos estudos culturais. Petrópolis: Vozes, 2008. p. 7-72.

WORTMANN, M. L. C.; VEIGA-NETO, A. Estudos culturais da ciência \& educação. Belo Horizonte: Autêntica, 2001.

WYZYKOWSKI, T. et al. A experimentação no ensino fundamental de ciências: a reflexão em contexto formativo. In: ENCONTRO NACIONAL DE PESQUISA EM EDUCAÇÃO EM CIÊNCIAS, 8., 2011, Campinas. Atas... Disponível em: < http://www.nutes.ufrj.br/ abrapec/viiienpec/resumos/R1296-1.pdf >. Acesso em: 29 jan. 2014.

ZULIANI, S. R. Q. A. A utilização da metodologia investigativa na aprendizagem de química experimental. 2000. 288 f. Dissertação (Mestrado) - Faculdade de Ciências, Universidade Estadual Paulista, Bauru, 2000.

Artigo recebido em 08/05/13. Aceito em 29/11/13. 